\title{
Elevated CCL2 causes Leydig cell malfunction in metabolic syndrome
}

\author{
Qingkui Jiang, ${ }^{1}$ Constanze C. Maresch, ${ }^{1}$ Sebastian Friedrich Petry, ${ }^{1}$ Agnieszka Paradowska-Dogan, ${ }^{2}$ \\ Sudhanshu Bhushan, ${ }^{3}$ Yongsheng Chang, ${ }^{4}$ Christine Wrenzycki, ${ }^{5}$ Hans-Christian Schuppe, ${ }^{6}$ \\ Petr Houska, ${ }^{17}$ Michaela F. Hartmann, ${ }^{8}$ Stefan A. Wudy, ${ }^{8}$ Lanbo Shi, ${ }^{9}$ and Thomas Linn ${ }^{1}$ \\ ${ }^{1}$ Clinical Research Unit, Centre of Internal Medicine, Justus-Liebig-University (JLU), Giessen, Germany. ${ }^{2}$ Department of \\ Gynecological Endocrinology and Reproductive Medicine, University Clinic Bonn, Bonn, Germany. ${ }^{3}$ Institute of Anatomy \\ and Cell Biology, Department of Reproductive Biology, JLU, Giessen, Germany. ${ }^{4}$ Tianjin Key Laboratory of Cellular and \\ Molecular Immunology, Key Laboratory of Immune Microenvironment and Disease (Ministry of Education), Department \\ of Physiology and Pathophysiology, Tianjin Medical University, Tianjin, China. ${ }^{5}$ Department of Molecular Reproductive \\ Medicine, Clinic for Veterinary Obstetrics, Gynecology and Andrology, and ${ }^{6}$ Department of Urology, Pediatric Urology and \\ Andrology, JLU, Giessen, Germany. ${ }^{7}$ ANOVA, Karolinska University Hospital and Karolinska Institutet, Stockholm, Sweden. \\ ${ }^{8}$ Steroid Research and Mass Spectrometry Unit, Division of Pediatric Endocrinology and Diabetology, Center of Child \\ and Adolescent Medicine, JLU, Giessen, Germany. ${ }^{9}$ Public Health Research Institute, New Jersey Medical School, Rutgers \\ Biomedical and Health Sciences, Rutgers, The State University of New Jersey, Newark, New Jersey, USA.
}

Metabolic syndrome (MetS), which is associated with chronic inflammation, predisposes males to hypogonadism and subfertility. The underlying mechanism of these pathologies remains poorly understood. Homozygous leptin-resistant obese $d b / d b$ mice are characterized by small testes, low testicular testosterone, and a reduced number of Leydig cells. Here we report that IL-1及, CCL2 (also known as MCP-1), and corticosterone concentrations were increased in the testes of $d b / d b$ mice relative to those in WT controls. Cultured murine and human Leydig cells responded to cytokine stress with increased CCL2 release and apoptotic signals. Chemical inhibition of CCL2 rescued Leydig cell function in vitro and in $d b / d b$ mice. Consistently, we found that Cc/2-deficient mice fed with a high-energy diet were protected from testicular dysfunction compared with similarly fed WT mice. Finally, a cohort of infertile men with a history of MetS showed that reduction of CCL2 plasma levels could be achieved by weight loss and was clearly associated with recovery from hypogonadism. Taken together, we conclude that CCL2-mediated chronic inflammation is, to a large extent, responsible for the subfertility in MetS by causing damage to Leydig cells.

Conflict of interest: The authors have declared that no conflict of interest exists.

Copyright: (c) 2020, Jiang et al. This is an open access article published under the terms of the Creative Commons Attribution 4.0 International License.

Submitted: November 8, 2019 Accepted: September 30, 2020 Published: November 5, 2020

Reference information: /CI Insight. 2020;5(21):e134882. https://doi.org/10.1172/jci. insight.134882.

\section{Introduction}

Infertility affects $10 \%$ of couples worldwide, and male factors contribute to more than $40 \%$ of the infertility cases $(1,2)$. Metabolic syndrome (MetS) is a cluster of abnormalities including type 2 diabetes, obesity, dyslipidemia, and hypertension that has been proposed as a potential cause of male infertility (3-6). MetS has been associated with a higher incidence of male infertility compared with healthy men, as indicated by decreased serum testosterone/estrogen ratio and poor semen quality. However, the mechanisms underlying the MetS-induced male reproductive disorders remain unclear (7-12)

The testis is the male gonad with functions of spermatogenesis and androgen production. Inflammation within the testis has been postulated as an important etiological factor of male infertility (1316). Disrupted spermatogenesis has been reported when orchitis is induced by lipopolysaccharide (LPS) injection (17). Although not as highly elevated as compared with severe infection, increased blood levels of cytokines are characteristics of $\operatorname{MetS}(18,19)$. In adipose and liver tissue, enhanced expression of tumor necrosis factor- $\alpha$ (TNF- $\alpha$ ), interleukin-1 $\beta$ (IL-1 $\beta$ ), interleukin-6 (IL-6), and C-C motif chemokine ligand 2 (CCL2), also known as monocyte chemoattractant protein-1 (MCP-1), was reported (20-23). These inflammatory factors are causative and predictive for many organ-specific diseases associated with MetS (24), yet the mechanism linking chronic inflammation to testicular impairment in the setting of MetS has not been addressed. 
Testicular interstitium contains several cell types, including Leydig cells, macrophages, and endothelial cells, capable of producing proinflammatory cytokines such as IL-1 $\beta$, IL-6, and TNF- $\alpha$ to modulate testis functions (25-29). CCL2 is a chemokine expressed constitutively in testis by Leydig cells and peritubular cells $(30,31)$. In obese subjects, increased abundance of CCL2 was observed in both white adipose tissue and plasma $(32,33)$. Mouse models have also demonstrated that the expression of CCL2 increases with body weight increase and contributes to insulin resistance $(34,35)$. By contrast, CCL2 deficiency abrogates inflammation and steatosis secondary to high-fat diet (36). Elevated CCL2 level in the testis of experimental autoimmune epididymo-orchitis indicates that CCL2 might regulate testicular functions in inflammation (37); however, its potential roles have not been explored.

The C57BLKS-Lepr ${ }^{d b}$ mouse ( $d b / d b$ mouse) is homozygous for a mutation in its leptin receptor (Lepr) gene and is a well-established animal model for type 2 diabetes and MetS. Male $d b / d b$ mice fail to reproduce, but testicular factors associated with the full MetS phenotype, including type 2 diabetes, have not been investigated to our knowledge. A neuron-specific transgenic expression of the Lepr transgene rescues the MetS phenotype and reproductive capacity of male $d b / d b$ mice, implying that the MetS phenotype, rather than testicular deficiency of $L e p r$, leads to infertility in male $d b / d b$ mice (38).

Based on these considerations, we hypothesized that proinflammatory cytokines in the testis of $d b / d b$ mice would play an important role in reflecting conditions of human MetS. We examined testes in diabetic $d b / d b$ mice with fully manifested MetS and identified Leydig cells as the foremost target of obesity-induced inflammation. We then established various other mouse and cell culture models to dissect male factor subfertility in MetS and the role of inflammation in it. In addition, a clinical trial in infertile men was performed to further test our hypothesis and explore potential treatment strategies.

\section{Results}

MetS and male infertility. $d b / d b$ mice showed significantly higher body weight at 6 weeks of age compared with that of WT and BKS(D)-Lepr $r^{\mathrm{db}+/-} / \mathrm{JOrlRj}(d b /+)(d b /+)$ mice (Figure 1A and Supplemental Figure 1A; supplemental material available online with this article; https://doi.org/10.1172/jci.insight.134882DS1). Fasting blood glucose levels of $d b / d b$ mice were markedly higher than those of WT and $d b /+$ mice at 12 and 24 weeks (Figure 1B). To investigate the reproductive function in these mice, testis weights were assessed at different ages, and sperm parameters were measured at 24 weeks. The testis of $d b / d b$ mice had comparable weight (Figure $1 C$ ) and histology (Supplemental Figure 1B) as $d b /+$ and WT mice at 6 weeks. However, $d b / d b$ mice showed significantly lower testis weight than that of WT and $d b /+$ mice at 12 and 24 weeks (Figure 1C), indicating testicular disturbance developed with progression of full MetS. Consistently, $d b / d b$ mice had reduced seminiferous tubule diameter (Supplemental Figure 1C) and seminiferous epithelium thickness (Supplemental Figure 1D), disturbed spermatogenesis (Supplemental Figure 1E), and increased germ cell apoptosis (Supplemental Figure 2). Moreover, epididymal sperm from $d b / d b$ mice showed poor motility, $70 \% \pm 10 \% d b / d b$ sperm vs. $39 \% \pm 5 \%$ WT sperm, and 38\% $\pm 6 \% d b /+$ sperm were immobile $(P<0.05$, Figure 1D). The sperm density declined from $6.0 \pm 0.9 \times 10^{6} / \mathrm{mL}$ in WT mice and $6.5 \pm 0.6 \times 10^{6} / \mathrm{mL}$ in $d b /+$ to $2.2 \pm 1.1 \times 10^{6} / \mathrm{mL}$ in $d b /$ $d b$ mice $(P<0.01$, Figure 1E). Furthermore, the DNA fragmentation index (DFI) indicated impaired DNA integrity in sperm from $d b / d b$ mice $(P<0.01$, Figure $1 \mathrm{~F})$, which could be responsible for the complete failure of reproduction of $d b / d b$ males as compared with WT males in controlled breeding experiments ( 0 vs. $5.75 \pm$ 0.75 litters) (Table 1). Concordantly, developmental rates of oocytes fertilized in vitro with sperm from $d b / d b$ mice up to the morula/blastocyst stage were significantly lower than those of oocytes fertilized with WT sperm (Table 2). Because male $d b /+$ mice have been characterized by normal fertility in various studies (38-42), we focused on comparing $d b / d b$ with WT mice in the following experiments unless stated otherwise.

Loss of Leydig cells. The most conspicuous phenotype in testis sections of $d b / d b$ mice was a decrease of Leydig cell numbers (Figure 2A). Immunostaining of INSL3, a peptide uniquely produced by Leydig cells, revealed a total loss of its expression in the testis of $d b / d b$ mice at 12-24 weeks (Figure $2 \mathrm{~B}$ ), which was further confirmed by quantitative Western blot analysis (Figure 2C). Significant reduction of steroidogenic acute regulatory protein (STAR), a rate-limiting enzyme in the production of androgen, was observed at both the protein (Figure 2D) and mRNA levels (Figure 2E) along with the reduction of mRNA levels of other steroidogenic genes (Hsd17b1, Cyp11a1, and Cyp17al) in the testis of $d b / d b$ mice (Figure 2E). Consequently, testosterone levels in both serum and testicular interstitial fluid (TIF) of $d b / d b$ mice were markedly reduced compared with those of WT mice (Figure 2, F and G). These results suggest that Leydig cells, known as the primary source of androgens, were reduced in number with potentially impaired function in the testis of $d b / d b$ mice. 

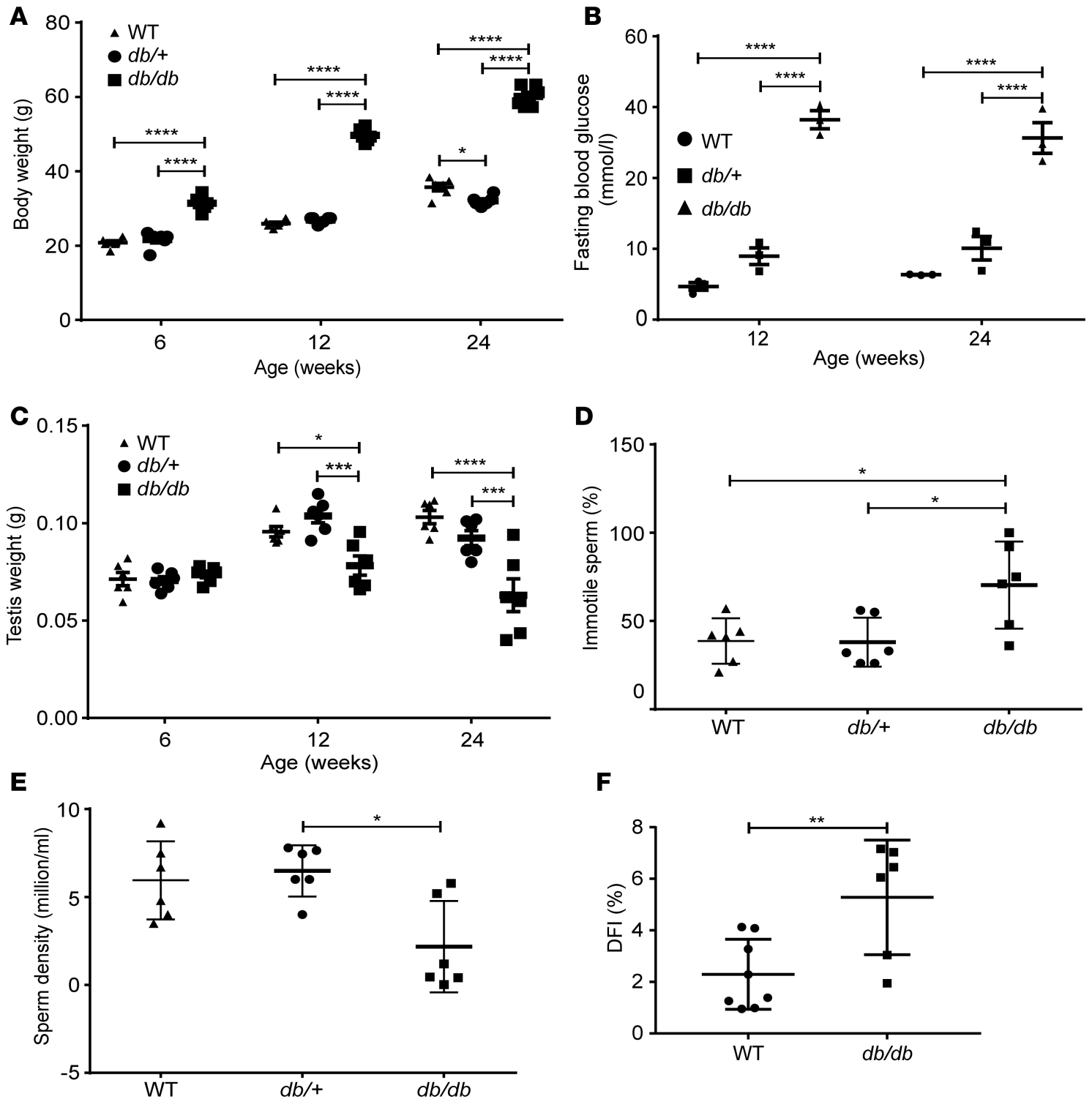

Figure 1. Characteristics of phenotype and reproductivity of $d \mathbf{d b} / \mathbf{d b}$ mice. (A) Body weight of WT, $d b /+$, and $d b / d b$ mice $(n=6)$ at 6,12 , and 24 weeks of age. (B) Blood glucose levels in WT, $d b /+$, and $d b / d b$ mice at 12 and 24 weeks of age $(n=6)$. (C) Testis weight of WT, $d b /+$, and $d b / d b$ mice at 6,12 , and 24 weeks of age; $n=3$ in each group. ( $\mathbf{D}$ and $\mathbf{E})$ Sperm motility (D) and density (E) in 12- to 24-week-old mice; $n=6$ in each group. (F) DNA fragmentation index (DFI) of epididymal sperm from age-matched 12- to 24-week-old $d b / d b(n=6)$ and WT $(n=7)$ mice. Data represent 1 of 3 independent experiments and are shown as means \pm standard error of the mean (SEM). Student's 2 -tailed $t$ test was used to compare means between 2 groups, and 1-way ANOVA was used to compare means between 3 groups followed by Tukey's post hoc comparisons. ${ }^{*} P<0.05,{ }^{* *} P<0.01,{ }^{* *} P<0.001,{ }^{* * *} P<0.0001$.

Expression of fertility genes and testicular cytokine activity. We next examined whether inflammatory cytokines were involved in infertility caused by MetS. Quantitative real-time PCR (RT-qPCR) analysis of mRNA isolated from testicular tissue showed downregulation of genes related to spermatogenesis (Acsbg2, Adcy10, Catsper1, Catsper4, and Crisp2) and fertilization (Akap4, Trim36, and Plcz1) and upregulation of genes associated with oxidative stress (Cdo1, Fos, and Uchl1) in the testis of $d b / d b$ mice (Figure 3A and Table 3). Notably, elevated Ill6 and Nfkbia mRNA indicated the activation of inflammatory pathways. Analysis of the expression of other proinflammatory markers revealed $I l b$ as the only gene measured with increased expression in both adipose tissue (Figure $3 \mathrm{~B}$ ) and testes (Figure $3 C$, Supplemental Figure 3) of $d b / d b$ mice. Elevation of testicular IL-1 $\beta$ protein level in $d b / d b$ mice, as compared with WT mice, was confirmed by ELISA using whole testis lysates (Figure 3D). These results imply that IL-1 $\beta$-mediated inflammation might play a causative role in the pathogenesis of subfertility in $d b / d b$ mice. 
Table 1. Assessment of fertility of WT versus $d b / d b$ mice

\begin{tabular}{lcc}
\hline Male mice & Female mice & Litters \\
WT & WT & $5.75 \pm 0.75$ \\
$d b / d b$ & WT & 0
\end{tabular}

Offspring after natural mating of male WT or $d b / d b$ with WT females at 12 weeks of age $(n=5)$. Data are shown as means \pm SEM.

Upregulation of CCL2. Because CCL2 was also suggested to be involved in MetS, expression of this proinflammatory chemokine was investigated. First, we examined the distribution of CCL2 protein in the testis. Immunofluorescence staining of WT testis revealed that Leydig cells had the capacity to produce substantial amounts of CCL2, as demonstrated by double staining of STAR and CCL2 (Figure 4A). Because no STAR-positive cells were observed, but CCL2 protein was still detected in the testis of $d b / d b$ mice at 12-24 weeks, it is evident that CCL2 was expressed by testicular cells other than Leydig cells, presumably macrophages and/or peritubular cells. CCL2 might thus be a paracrine factor that contributes to Leydig cell loss in $d b / d b$ mice. A significant increase of CCL2 was confirmed at mRNA and protein levels in both testes and adipose tissue (Figure 4, B-F) of $d b / d b$ mice at 12-24 weeks of age.

Macrophage profile changes associated with MetS. Because Leydig cells are positionally and functionally associated with testicular macrophages, we reasoned that properties of resident macrophages might be a factor influencing Leydig cells' viability. We therefore analyzed macrophage populations in the testis by flow cytometry (Figure 5, A and B). Although the percentage of $\mathrm{F} 4 / 80^{+} \mathrm{CD} 45^{+}$was not significantly different between testis of $d b / d b$ and WT mice, the proportion of proinflammatory CD $64^{+} \mathrm{F} 4 / 80^{+}$macrophages was reduced in $d b / d b$ mice (Figure 5, A and B). F4/80 immunohistochemical staining showed a clear reduction of macrophages in the testis of $d b / d b$ mice (Supplemental Figure 4), indicating that the absolute $\mathrm{F} 4 / 80^{+}$macrophages were reduced proportionally to the total cell number in testis of $d b / d b$ mice, which resulted in the comparable percentage of $\mathrm{F} 4 / 80^{+} \mathrm{CD} 45^{+}$in the testis of $d b / d b$ and WT mice. Increased $\mathrm{Il}-10$ mRNA level in the testis of $d b / d b$ mice suggested a shift of macrophage population to the antiinflammatory M2 phenotype (Figure 5C), which was supported by the upregulated arginase 1 (Arg1) mRNA level and comparable nitric oxide synthase 2 (Nos2) levels in the testis of $d b / d b$ mice as compared with those in the testis of WT mice (Figure 5D). Interestingly, while corticosterone was undetectable in the TIF of WT mice, its level in $d b / d b$ mice was significantly increased in both serum and TIF (Figure 5E).

$C C L 2$ expression is induced by $I L-1 \beta$ in vitro. Reduced inflammatory macrophages in the testis of $d b / d b$ mice indicated that different sources were responsible for the increased CCL2 expression in the testis. One of the candidates would be Leydig cells because of their constitutive expression of CCL2 (30,31), which might be increased in the presence of proinflammatory cytokines. To test this hypothesis, we mimicked the testicular microenvironment by treating the murine Leydig cell line MLTC-1 (Figure 6) and primary human Leydig cells (HLC) (Figure 7) with hCG and/or IL-1 $\beta$. First, we showed that CCL2 is constitutively expressed in MLTC-1 cells (Figure 6A). Addition of IL-1 $(1 \mathrm{ng} / \mathrm{mL})$ significantly induced CCL2 protein levels along with decreased expression of a steroidogenic enzyme, CYP17A1, in MLTC-1 cells (Figure 6, B-D). These changes were accompanied by induction of apoptosis, as measured by cleaved caspase- 3 levels in MLTC-1 (Figure 6, C and D). Similarly, IL-1 $\beta$ induced proinflammatory response in HLC, as evidenced by increased

Table 2. In vitro fertilization result with sperm from WT versus $d b / d b$ males

\begin{tabular}{lccccc}
\hline & Rate of degenerated oocytes after IVF & Cleavage rate & \multicolumn{2}{c}{ Developmental rate $^{\mathrm{A}}$} & Developmental rate $^{\mathrm{B}}$ \\
WT & $30.5 \pm 25.7$ & $76.5 \pm 21.3$ & $25.0 \pm 13.0$ & $32.8 \pm 13.6$ \\
$d b / d b$ & $43.3 \pm 20.1^{C}$ & $62.9 \pm 19.1^{\complement}$ & $7.2 \pm 8.7^{D}$ & $13.6 \pm 19.8^{D}$
\end{tabular}

Rates of degenerated oocytes after in vitro fertilization (IVF), cleavage rates and developmental rates employing sperm from either WT or $d b / d b$ male mice aged 8 weeks. Data are shown as mean \pm standard deviation. $N=6$ independent experiments. Student's 2-tailed $t$ test was used to compare means between 2 groups. ${ }^{A}$ Rate calculated on the number of zygotes. ${ }^{B}$ Rate calculated on the number of cleaved embryos. ${ }^{\mathrm{C}}$ Nonsignificant. ${ }^{\mathrm{D}} \mathrm{P}<0.05$. 
A

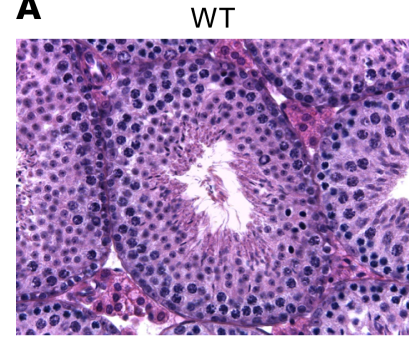

C
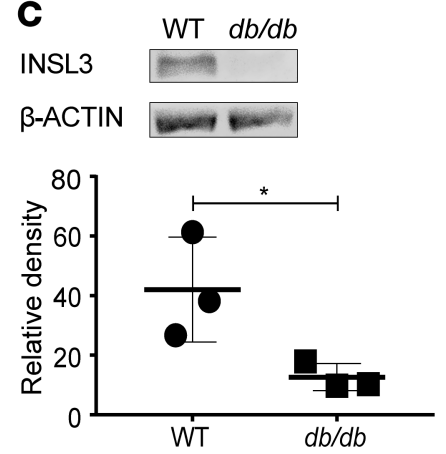

F

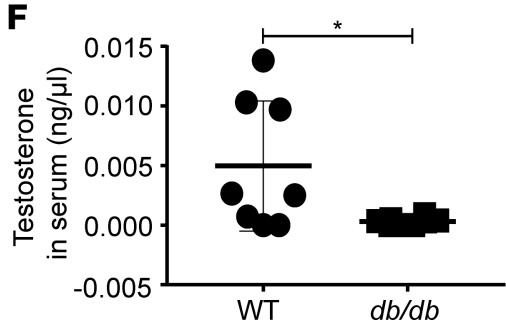

D $d b / d b$
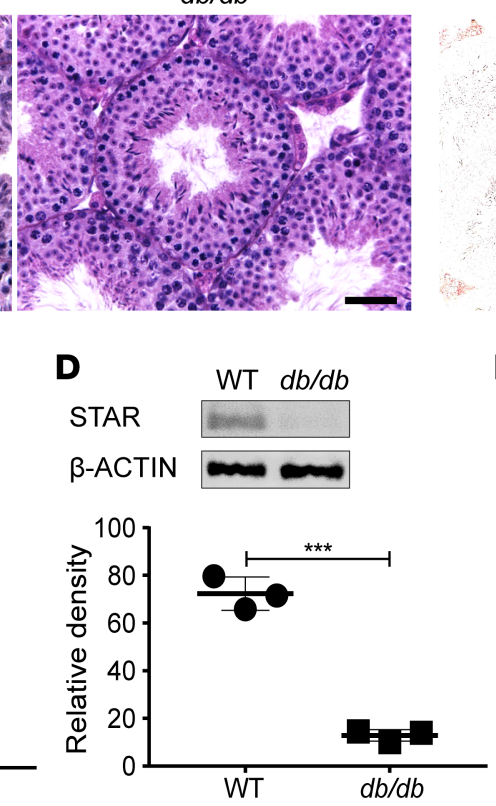

G

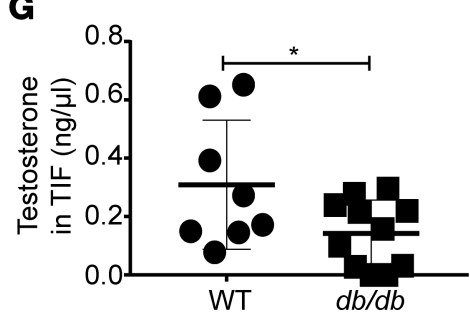

Figure 2. $\mathbf{d b} / \mathbf{d} \mathbf{b}$ mice showed impaired expression of specific Leydig cell products. (A and B) H\&E (A) and insulin-like 3 (INSL3) (B) staining on representative testicular sections; scale bar: $20 \mu \mathrm{m}$. (C and D) Protein expression of INSL3 (C) and STAR (D), respectively, as analyzed by Western blot. (E) mRNA levels of steroidogenic genes in WT and $d b / d b$ mice. (F and $\mathbf{G})$ Mean testosterone levels in serum (F) and testicular interstitial fluid (TIF) (G). Data given in C-G were from $n=3-8$ mice, 12-24 weeks old, in each group. Data are shown as means \pm SEM. Student's 2-tailed $t$ test was used to compare means between 2 groups. ${ }^{*} P<0.05,{ }^{* *} P<0.01,{ }^{* * *} P<0.001,{ }^{* * *} P<0.0001$.

CCL2 (at the mRNA and protein levels) and Ilb (on the mRNA level) expression, and inhibited STAR protein expression (Figure 7, A-F). The elevated VDAC-1 level in HLC after IL-1 $\beta$ treatment indicated onset of apoptosis (Figure 7, G and H) (43). Of note, activities of steroidogenic enzymes, IL-1 $\beta$ induction, and apoptotic events were partially rescued by administrating the CCL2 inhibitor Bindarit (Figure 7, A-H). These findings demonstrate that CCL2 induced by IL-1 $\beta$ was a proapoptotic factor for Leydig cells.

CCL2 inhibition improved hypogonadism in vivo. Chemical inhibition and B6.129S4-Ccl2 ${ }^{\mathrm{m} 1 \mathrm{Rol}}(\mathrm{Ccl} 2-\mathrm{KO})$ mice were used to further support the role of CCL2 in MetS-related subfertility. First, we treated $d b / d b$ mice with Bindarit $(100 \mathrm{mg} / \mathrm{kg} / \mathrm{d})$ or vehicle control $(0.5 \%$ methylcellulose $)$ by oral gavage. The effects of Bindarit were most pronounced on obesity as it significantly decreased the body weight after 4 weeks of treatment $(P<0.05$, Figure $8 \mathrm{~A})$. Significant decrease of blood glucose was observed in the treated group under random condition $(P<0.05$, Figure $8 \mathrm{~B})$. The Bindarit-treated $d b / d b$ mice showed higher testis/body weight ratio $(P<0.05$, Figure $8 \mathrm{C})$, thicker seminiferous epithelium $(P<0.0001)$, and more tubules with the highest Johnsen score $(P<0.001$, Supplemental Figure $5, \mathrm{~A}-\mathrm{E})$, indicating less structural damage and a functional restoration in testes of the treated group (44). In addition, the treated $d b / d b$ mice also had significantly reduced fasting blood glucose $(P<0.0001$, Figure $8 \mathrm{D})$ at the end of the experiment. Moreover, mice subjected to Bindarit had more favorable fasting serum insulin concentrations $(P<0.05$, Figure $8 \mathrm{E})$ as well as insulin sensitivity, with homeostatic model assessment (HOMA) index $P<0.001$ (Figure 8F). Concomitantly, elevated serum testosterone levels suggested improved hypogonadism $(P<0.05$, Figure $8 \mathrm{G})$ in the Bindarit group as compared with that of controls. These results imply that CCL2 inhibition attenuated MetS symptoms, including partial rescue of hypogonadism in $d b / d b$ mice. Next, we verified the findings 

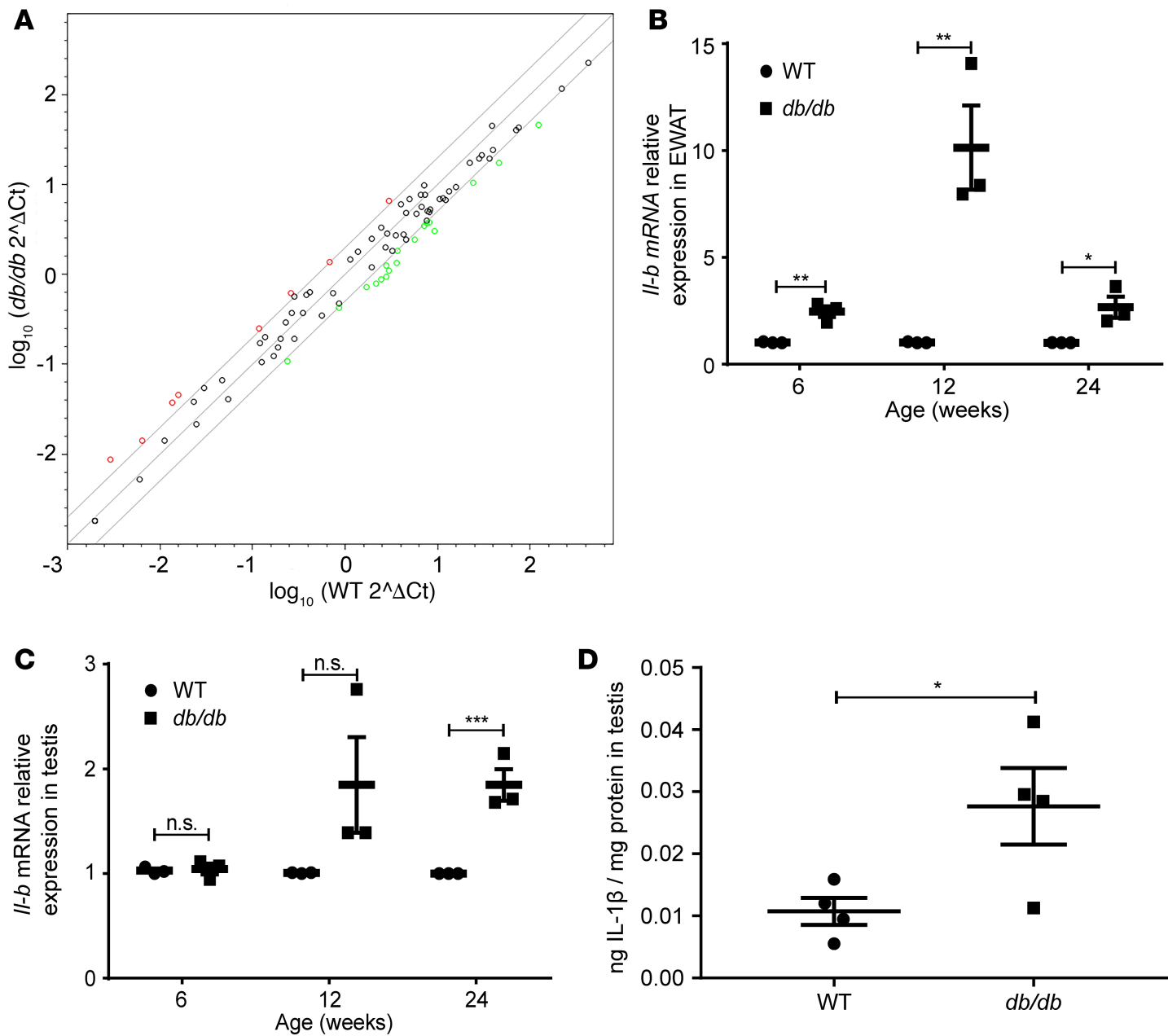

Figure 3. The expression of proinflammatory factors in testes of WT and $\mathbf{d} b / \mathbf{d} b$ mice. (A) Log transformation plot of the relative gene expression levels in testes of $d b / d b$ compared with in testes of WT mice. Colored dots indicate 2-fold or greater changes in mRNA levels (red, reregulation; green, downregulation). Samples were pooled from 4 mice in each group. (B) The $/ 1 b$ mRNA levels in epididymal white adipose tissue (EWAT). $N=3$ in each group. (C) The Ilb mRNA levels in testes. $N=3$ in each group. (D) IL-1 $\beta$ protein in testes. $N=4$ in each group. Data represent 1 of 3 independent experiments and are shown as means \pm SEM. Student's 2 -tailed $t$ test was used to compare means between 2 groups. ${ }^{*} P<0.05,{ }^{* *} P<0.01,{ }^{* * *} P<0.001$.

using a high-energy diet (HED) model. Ccl2-KO mice were subjected to HED for 12 weeks. Age-matched WT mice were used as controls. Although there was no statistical difference in body weight (Figure 8H, $P=$ 0.23 ) or fasting glucose levels (Figure 8I, $P=0.28$ ), the $C c l 2-\mathrm{KO}$ group exhibited higher testis/body weight ratio $(P<0.01$, Figure $8 \mathrm{~J})$, lower fasting insulin $(P<0.01$, Figure $8 \mathrm{~K})$, and restored insulin sensitivity (HOMA index, $P<0.01$, Figure 8L) as compared with HED-fed WT mice. Testosterone level (Figure 8M) and sperm density (Figure $8 \mathrm{~N}$ ) of the mutant mice were notably elevated. Consequently, $\mathrm{Ccl} 2-\mathrm{KO}$ group showed an improved IVF outcome as opposed to HED controls (Table 4). Together, these findings imply that genetic ablation of $C c l 2$ was capable of ameliorating hypogonadism in HED-fed mice.

CCL2 levels associated with hypogonadism. Infertile males participated in a weight reduction program as described in Supplemental Methods. At the start of the intervention, the mean body mass index (BMI) of all 20 participants (age $31.4 \pm 5.3$ ) was $36.9 \pm 3.5 \mathrm{~kg} / \mathrm{m}^{2}$, testosterone plasma levels were below normal range (255 \pm 91 , normal range 300-1200 ng/dL), and hypogonadism-related symptoms were observed throughout. The CCL2 level of this cohort was $535 \pm 140 \mathrm{pg} / \mathrm{mL}$ (normal range 200-722 pg/mL) (Supplemental Table 3) and was positively correlated with BMI and hemoglobin A1c (HbA1c) (Figure 9, A and B). At the end of the weight reduction program, CCL2 level was significantly reduced in the weight loss after intervention group (WLI), compared with its basal level (weight loss basal, WLB) and the non-weight loss after intervention group (NWLI) $(P<0.0001)$ (Figure 9C). Moreover, after intervention, CCL2 levels were found to be not only highly and positively correlated with MetS components BMI, HOMA, and the 
Table 3. Regulated genes in $d b / d b$ mice

\begin{tabular}{cccc}
\hline \multicolumn{2}{c}{ Overexpressed genes } & \multicolumn{2}{c}{ Underexpressed genes } \\
\hline Gene & Fold change & Cene & Fold change \\
Amh & 2.91 & Acsbg2 & -2.08 \\
\hline Cdos1 & 2.37 & Adcy10 & -2.73 \\
\hline Fos & 2.80 & Akap4 & -2.63 \\
\hline II16 & 2.22 & Catsper1 & -2.76 \\
\hline Lep & 2.98 & Catsper4 & -2.20 \\
Nfkbia & 2.03 & Crisp2 & -2.65 \\
Serpina5 & 2.18 & Cyp19a1 & -2.20 \\
\hline Uchl1 & 2.10 & Dnajc28 & -2.04 \\
& & Eif4g3 & -2.14 \\
& & Pcsk4 & -2.34 \\
& & Pdzd8 & -2.02 \\
& & Plcz1 & -3.05 \\
& & Slc26a8 & -2.92 \\
& & Srpk1 & -2.05 \\
& & Trim36 & -2.32 \\
& & Trpd5213 & -2.76 \\
& & Tsga10 & -2.31 \\
& & Ubap2 & -2.67 \\
& & &
\end{tabular}

Over- and underexpressed genes in $d b / d b$ mice. Genes with at least 2 -fold change are listed. Samples were pooled from 4 mice in each group.

proinflammatory factor sensitive C-reactive protein (sCRP) but also negatively correlated with hypogonadism indexes (testosterone and hypogonadism score). Similar correlations were observed between changes (basal vs. after intervention levels) of CCL2 and other parameters (Figure 9, D-I). These data suggest that in MetS, CCL2 is clinically relevant by predicting subjects' recovery from symptoms of hypogonadism.

\section{Discussion}

This study shows that chronic inflammation in full MetS can cause Leydig cell dysfunction and result in hypogonadism (Supplemental Figure 6). Increased IL-1 $\beta$ and CCL2 in adipose tissue and testes were associated with significant impairment of sperm quality and fertility as well as deterioration of androgen synthesis, which was caused by a clear reduction of Leydig cells. When exposed to IL-1 $\beta$, Leydig cells showed enhanced CCL2 release, increased apoptotic signals, and dampened steroidogenesis. Inhibition of Ccl2 transcription prevented Leydig cell dysfunction that was induced by inflammation in MetS in both in vitro and in vivo models. In a clinical cohort, the critical role of CCL2 in MetS-related hypogonadism was further supported by its significant correlations with testosterone and hypogonadism score. These findings indicate that therapeutic targeting of CCL2 expression might be effective in men with subfertility caused by MetS.

The impact of MetS on sperm function in males is controversial (45). Rodent models of MetS, including genetic, drug, and diet-induced models (38, 46-50), have been established and employed to address differences between rodents and humans. The $d b / d b$ mouse model reflects the progress to full MetS characterized by concomitant type 2 diabetes mellitus along with obesity in a time-dependent fashion, and it is a validated and predictive animal model for the human condition (51). Indeed, we demonstrated in this study that $d b /$ $d b$ mice developed hypogonadism associated with MetS, which is closely comparable with the phenotypes in humans. In addition, mice made obese by feeding with HED showed reduced sperm motility and abnormal morphology, especially when elevated blood glucose levels occurred together with reduced blood testosterone concentrations (52). Hence, our findings in $d b / d b$ mice were further supported by using the HED model.

It has been established that MetS is associated with inflammation (53) and that inflammation of the genitourinary tract results in suboptimal male fertility (54). However, whether chronic inflammation associated with MetS leads to reproductive dysfunction in males remained unclear. Previous studies showed that cytokines are present in both tubules and the interstitial compartment of the testis (31). When injected into adult rodent testis in vivo, these cytokines trigger effector mechanisms to directly inhibit STAR 
A
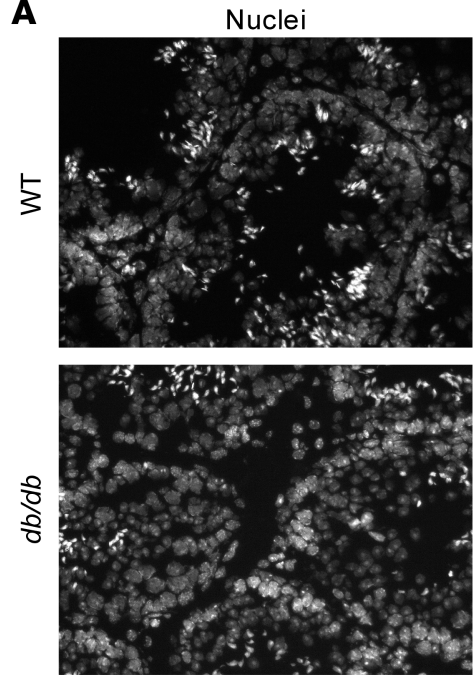

B

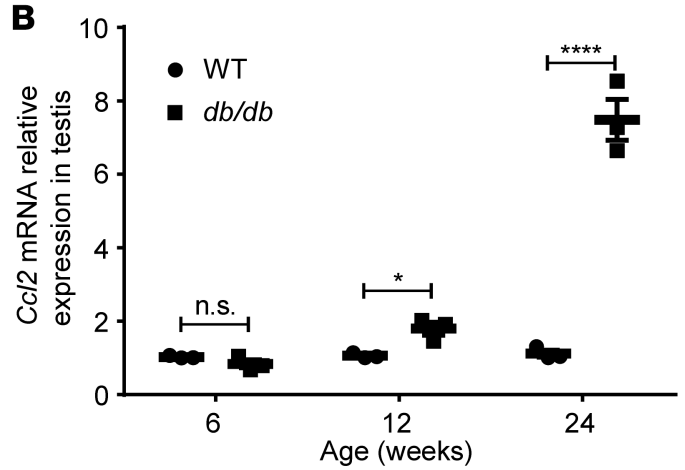

D

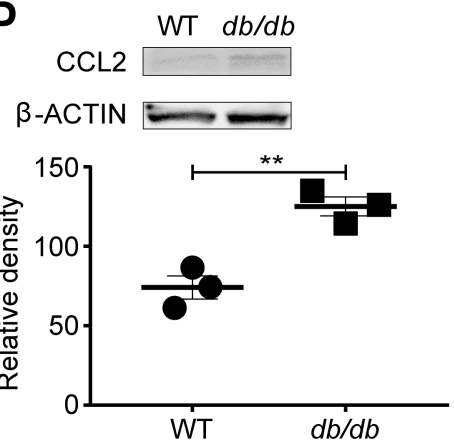

E
$\mathrm{CCL} 2$
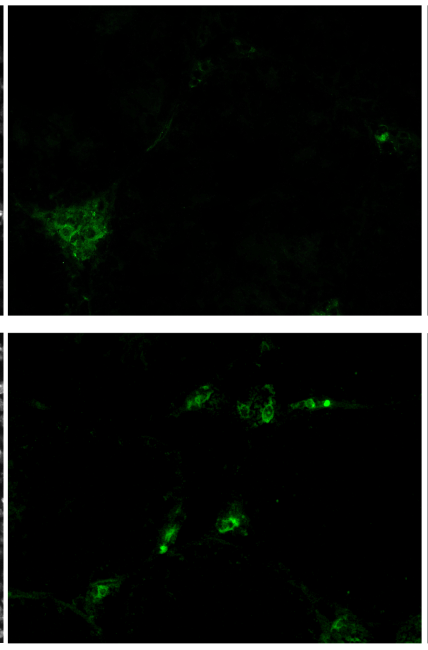

STAR
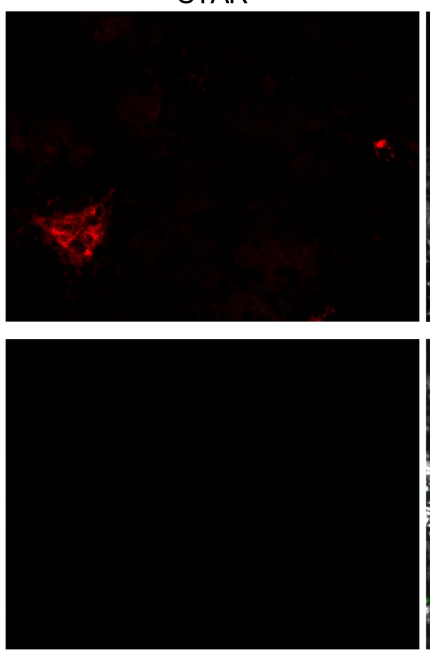

Overlay
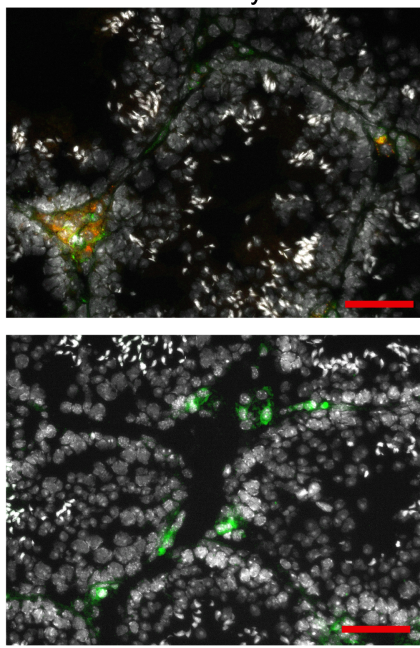

C
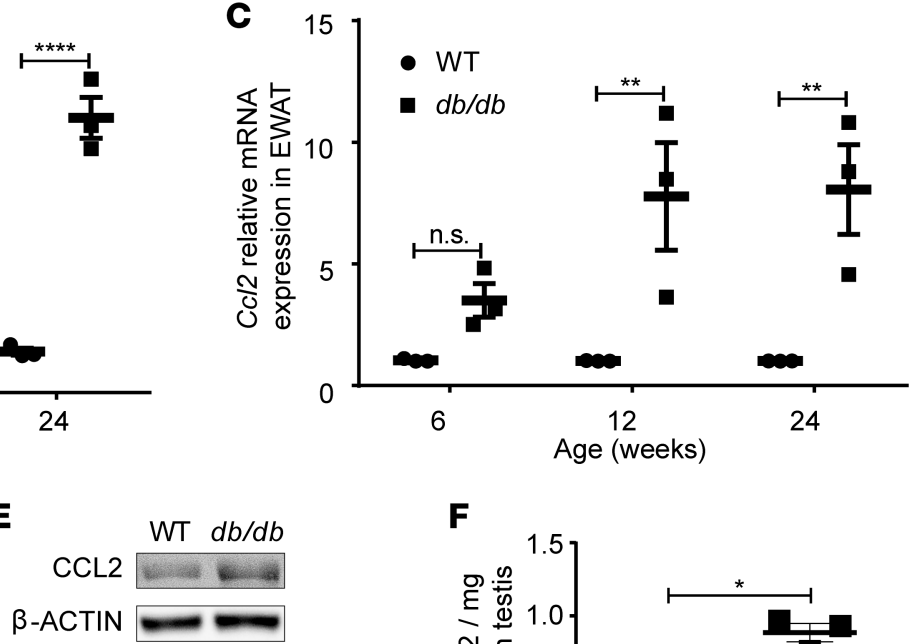

F

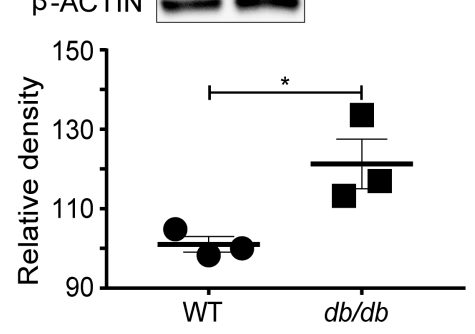

Figure 4. CCL2 expression was increased in $\mathbf{d} b / \mathbf{d} \boldsymbol{b}$ mice. (A) Representative sections show colocalization of CCL2 in STAR-positive cells of WT controls. Scale bar: $20 \mu \mathrm{m}$. CCL2 is present in STAR-negative cells close to the basal membrane of the tubuli. (B) The Ccl2 mRNA levels in testes. $N=3$ in each group. (C) The Ccl2 mRNA levels in EWAT. $N=3$ in each group. (D) CCL2 protein in testes as determined by Western blot and followed by quantification. $N=3$ in each group. (E) CCL2 protein expression in EWAT as determined by Western blot and followed by quantification. $N=3$ in each group. (F) CCL2 protein concentration in testes as determined by ELISA. $N=3$ in each group. Panels $\mathbf{A}, \mathbf{D}$, and $\mathbf{E}$ show representative images of 1 analysis per mouse. Data represent 1 of 3 independent experiments and are shown as means \pm SEM. Student's 2-tailed $t$ test was used to compare means between 2 groups. ${ }^{*} P<0.05,{ }^{* *} P<0.01,{ }^{* * * *} P<0.0001$.

expression and steroidogenesis in Leydig cells (55). Administration of $100 \mathrm{ng}$ IL-1 $\beta$ into the testes activates the JNK stress-related kinase pathway and increases E-selectin expression of microvascular endothelia and migration of immune cells (56). However, these investigations did not capture the main feature of MetS-related inflammation, the temporal and chronic increase of proinflammatory factors. Our results demonstrate that IL-1 $\beta$ not only is a potent inhibitor of Leydig cell function but also induces apoptosis of Leydig cells in culture. The source of IL-1 $\beta$, however, is yet to be determined. As IL-1 $\beta$ is critically involved in the translation of obesity-related inflammation into diseases of adjacent organs (57-59), it is plausible to assume that the IL-1 $\beta$ derived from the adipose tissue contributes, at least in part, to the increased IL- $1 \beta$ 
A
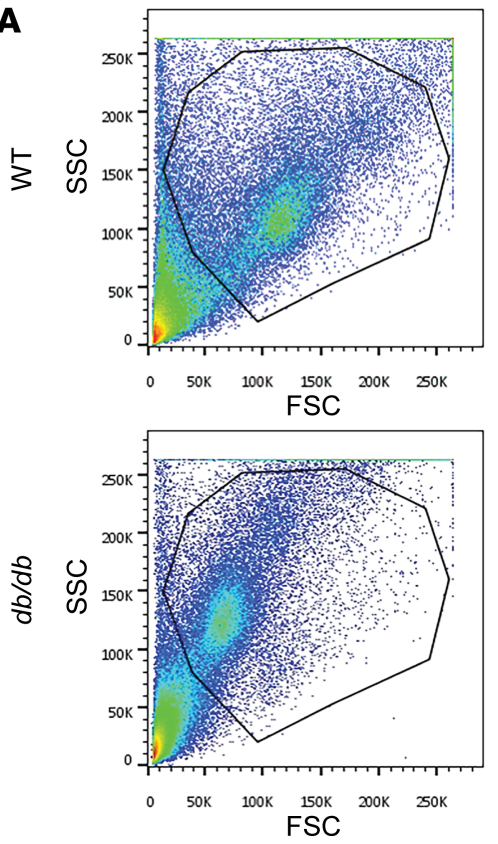

B
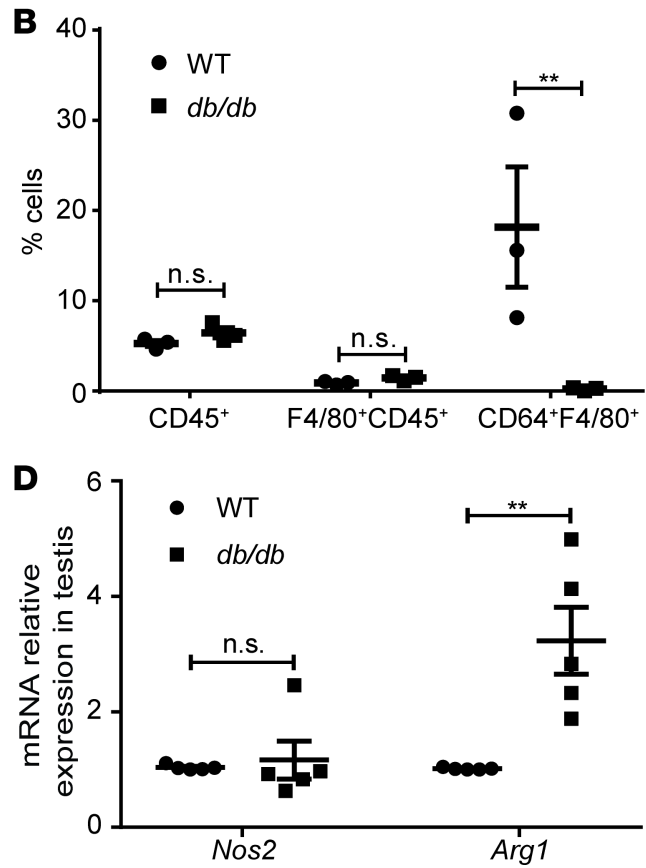
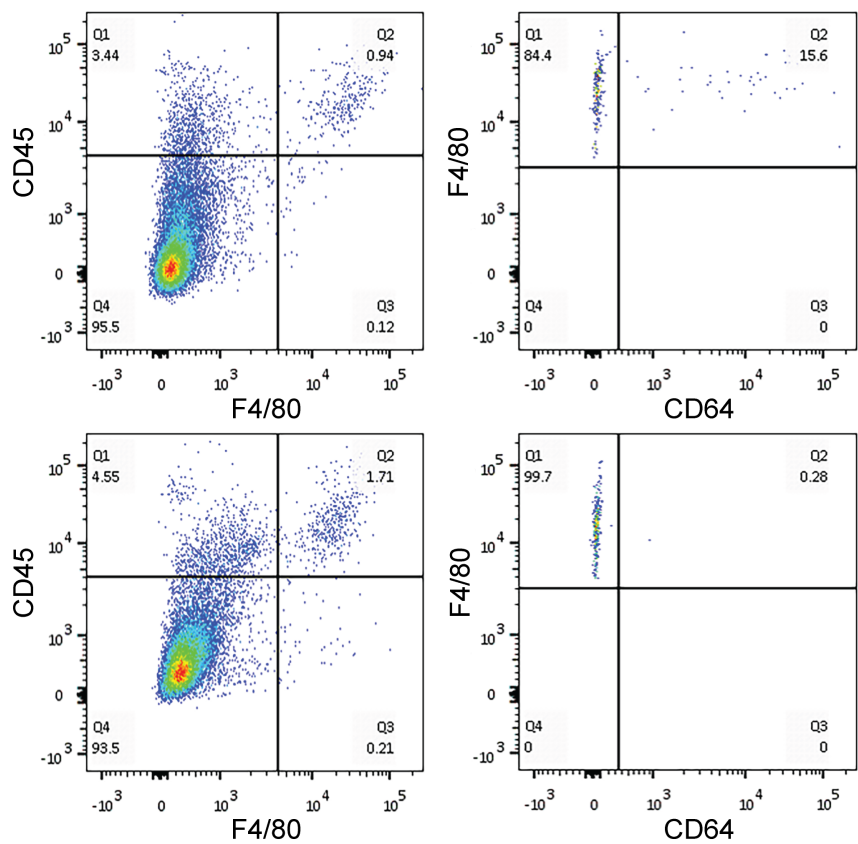

C

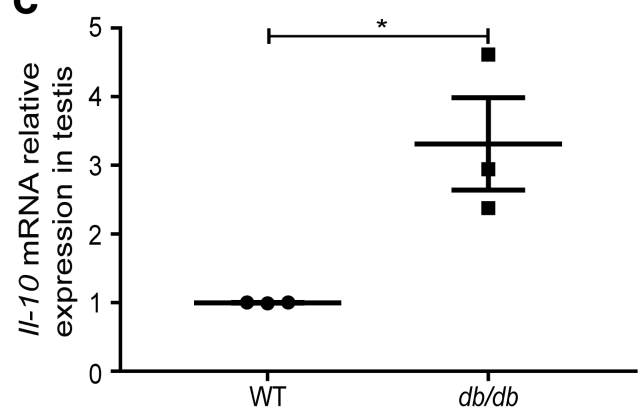

E

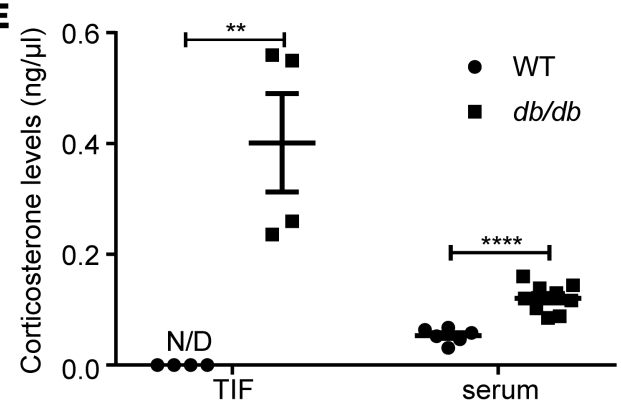

Figure 5. Testicular immune cells and corticosterone levels in $\mathbf{d b} \mathbf{b} \mathbf{d} \boldsymbol{b}$ mice. (A) Total testicular cells were isolated as described in Methods and examined by FACS. Representative flow cytometry gating schemes for testicular cells from WT and $d b / d b$ mice are demonstrated. The gating strategy is shown for CD45+F4/80+ and F4/80+CD64+ cells. (B) Frequencies of testicular $\mathrm{F} 4 / 80^{+}$within $\mathrm{CD} 45^{+}$cells and $\mathrm{CD} 64^{+}$within $\mathrm{F} 4 / 80^{+} \mathrm{CD} 45^{+}$cells from WT and $d b / d b$ mice. (C) The II-10 mRNA expression in testes. (D) The Nos2 and Arg1 mRNA expression in testes. (E) Corticosterone levels in TIF and serum. $N=3-8$ mice, 12 to 24 weeks old, in each group. Data are shown as means \pm SEM. Student's 2-tailed $t$ test was used to compare means between 2 groups. ${ }^{*} P<0.05,{ }^{* *} P<0.01$, ${ }^{* * *} P<0.0001$.

level in the testes and to subsequent Leydig cell malfunction. Indeed, macrophages in the adipose tissue from obese mice showed elevated glycolysis and oxidative phosphorylation, which increased activation of HIF- $1 \alpha$ and resulted in sustained local and systemic IL-1 $\beta$ production (60). Another potential source of IL-1 $\beta$ is the intratesticular cells, including macrophages and Leydig cells, that could be induced through either endocrine or paracrine signaling. Nevertheless, our results implicate the role of IL- $1 \beta$ in the crosstalk between adipose tissue and testis, which influences testicular structure and function in MetS. 
A

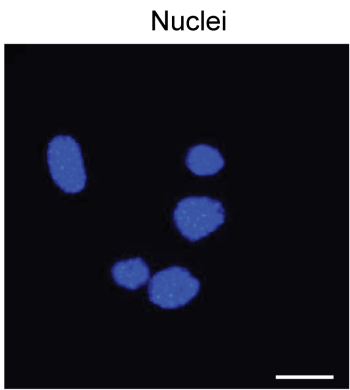

B

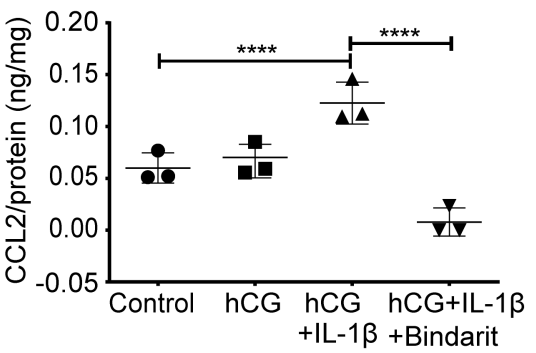

CCL2

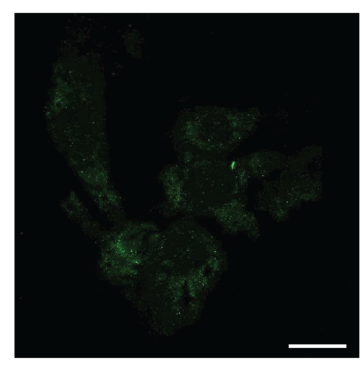

C

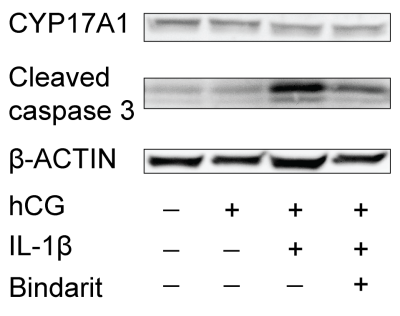

STAR

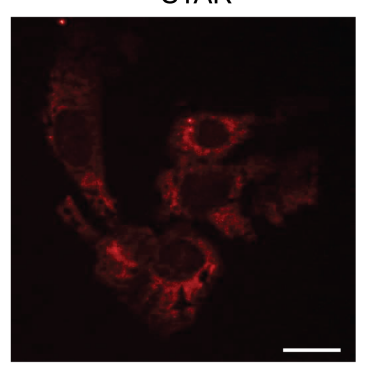

D

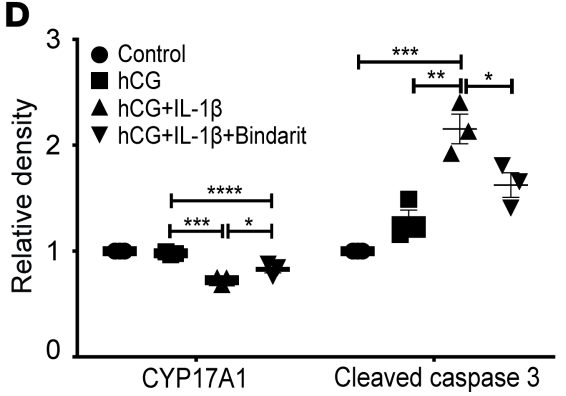

Figure 6. CCL2 regulated function and apoptosis of MLTC-1 cells. (A) Representative pictures showing MLTC-1 cells express CCL2 under basal cultivating conditions. (B) Amount of CCL2 in the culture medium. (C and D) Western blot analysis of CYP17A1 and cleaved caspase-3 in MLTC-1 cells after 48 hours' treatment with human chorionic gonadotropin (hCG) in the absence or presence of IL-1 $\beta(1 \mathrm{ng} / \mathrm{mL})$, with or without the CCL2 inhibitor Bindarit (100 $\mu \mathrm{M})$. $N=$ 3 in each group. Data represent one of 3 independent experiments and are shown as means \pm SEM. One-way ANOVA was used to compare means between groups followed by Tukey's post hoc comparisons. ${ }^{*} P<0.05,{ }^{* *} P<0.01,{ }^{* * *} P<0.0001$.

Another insight from the present data is that the inflammation-mediated subfertility in MetS is achieved by induction of CCL2. CCL2 has been demonstrated to be a potential intervention point for the treatment of diabetes (61). In fact, we detected that it was increased in the testis of $d b / d b$ mice as they progressed to obesity, adipose tissue inflammation, and infertility over a period of 24 weeks. Moreover, we observed that HED induced obesity in both WT and $C c l 2-K O$ mice, but the latter showed higher testis/body weight ratio, testosterone level, and sperm density. These findings suggest that obesity-associated IL-1 $\beta$ carries out its detrimental effect by elevating CCL2. As one of the principal chemokines in the testes, CCL2 is primarily released from Leydig and peritubular cells $(30,31)$. Increased secretion of CCL2 would be expected to attract more monocytes, but this was not obvious with cell cytometry analysis in the testis of $d b / d b$ mice in our study. This observation together with results of our in vitro models suggest that CCL2 impairs male fertility by inducing Leydig cell loss in a paracrine manner rather than by chemoattractantly recruiting monocytes. Indeed, injecting exogenous testosterone, which mimics Leydig cell function, can partially restore glucose intolerance and insulin resistance in male $d b / d b$ mice (39). Previous findings showed that CCL2 directly induced podocyte apoptosis in diabetic conditions, which was significantly ameliorated by the inhibition of cysteine-cysteine chemokine receptor 2, a CCL2 receptor (62). The specific mechanism(s) of CCL2-induced apoptosis remains elusive. It has been shown that the cytotoxic effect of CCL2 is probably mediated by oxidative stress in retinal detachment-induced photoreceptor apoptosis (63). We observed several genes that were upregulated in the testis of $d b / d b$ mice, including Cdo1 (64, 65), Fos (66), and Uchl1 (67), which have been reported to play roles in the oxidative stress response. Further, VDAC-1, a molecule that links apoptosis and oxidative stress (68), was regulated in human Leydig cells with CCL2. These results indicate that CCL2 likely exerts its cytotoxic effect through inducing oxidative stress.

As the numbers of both testicular macrophages and Leydig cells are reported to increase from birth to adulthood at a relatively constant rate, the current concept is that the two cell types are not only structurally but also functionally coupled under normal conditions (69). The reduction of $\mathrm{F} 4 / 80^{+}$macrophages might be caused by the reduction of Ins3L-positive Leydig cells in MetS. The lower percentage of M1 phenotype macrophages in the testis of $d b / d b$ mice can be explained by the significantly increased levels of corticosterone in serum and TIF in $d b / d b$ mice. Glucocorticoid release from the adrenal gland to the blood is facilitated in $d b / d b$ mice with full MetS $(70,71)$, and glucocorticosteroids are widely known for their immunosuppressive role in chronic inflammatory diseases (72). In testes, corticosterone promotes polarization of 
A
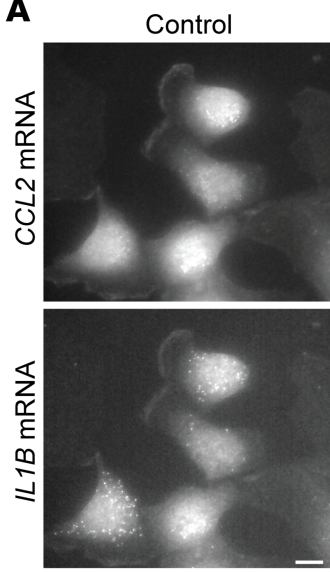

D

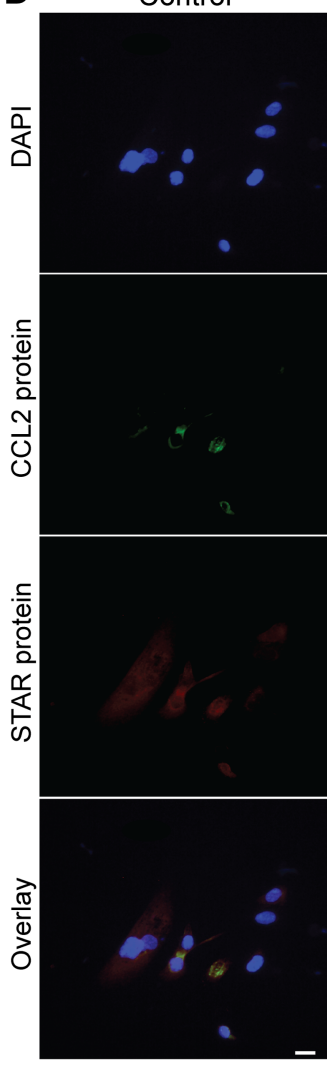

G

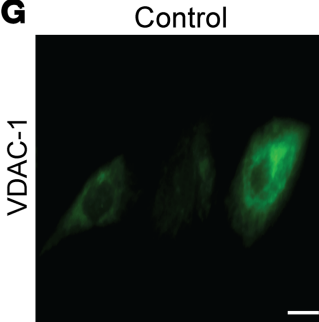

$\mathrm{hCG}$

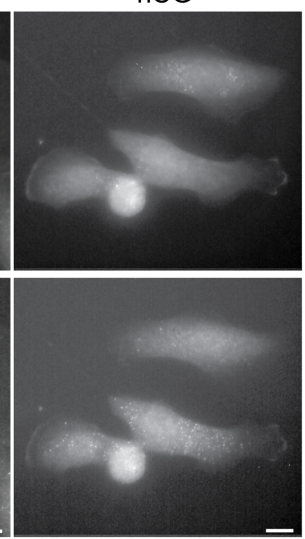

hCG
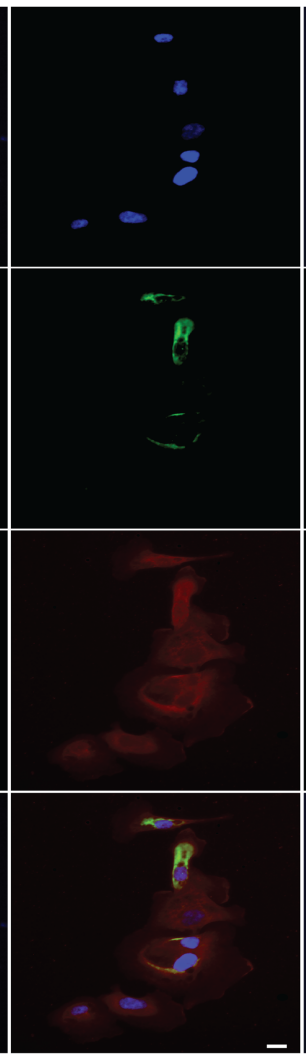

$\mathrm{hCG}$

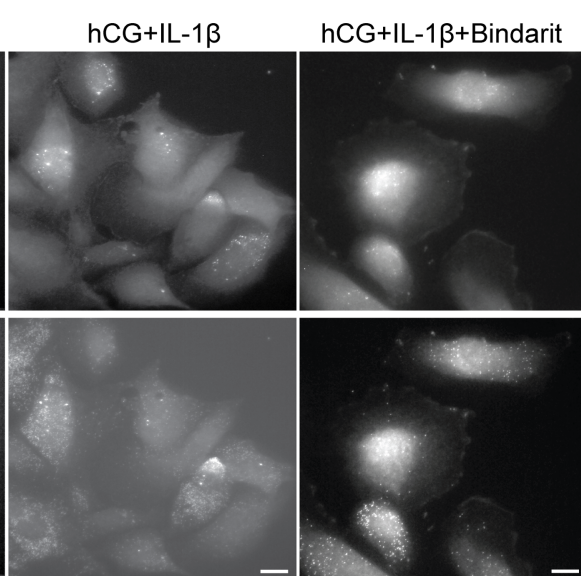

$h C G+\mid L-1 \beta$
B
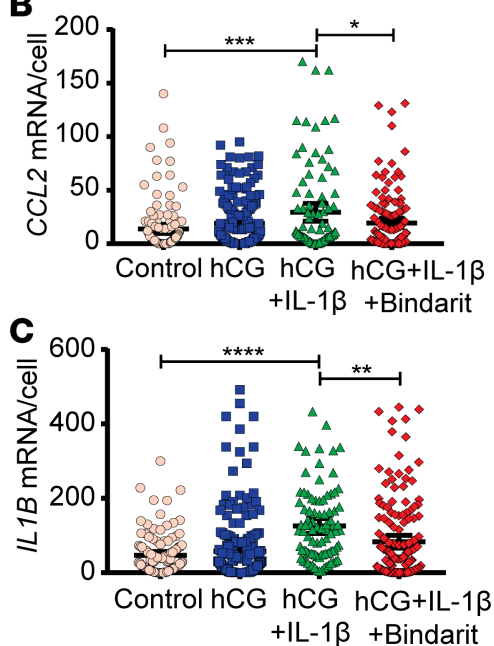

E
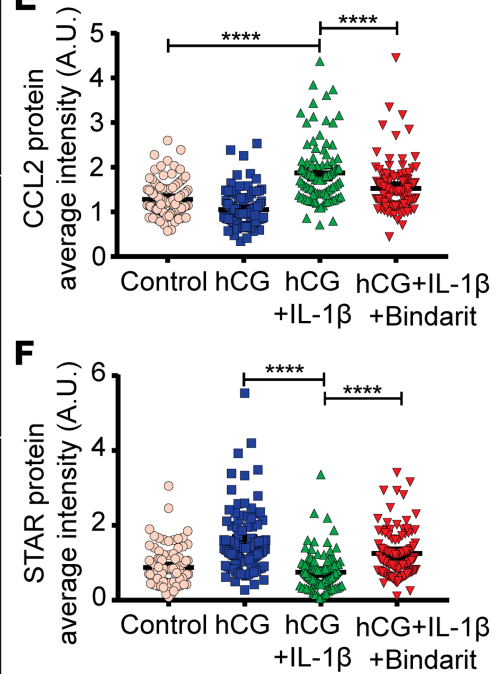

Figure 7. CCL2 regulated function and apoptosis of primary human Leydig cells. (A-C) Representative pictures showing CCL2 and ILB mRNA expressions in HLC after 48 hours' treatment with hCG in the absence or presence of IL-1 $\beta$ ( $1 \mathrm{ng} / \mathrm{mL})$, with or without Bindarit (100 $\mu \mathrm{M})(\mathbf{A})$, followed by quantification: number of CCL2 (B) and ILB (C) mRNA molecules per HLC. (D-F) Representative pictures showing CCL2 and STAR protein expressions in HLC after 48 hours' treatment with hCG in the absence or presence of IL-1 $\beta$ ( $1 \mathrm{ng} / \mathrm{mL}$ ), with or without Bindarit (100 $\mu \mathrm{M})$ (D), followed by quantification: average fluorescence intensity of CCL2 (E) and STAR (F) per HLC. (G and H) Representative pictures showing voltage-dependent anion-selective channel 1 (VDAC-1) protein expression in HLC after 48 hours' treatment with hCG in the absence or presence of IL-1 $\beta$ ( 1 ng/mL), with or without Bindarit (100 $\mu \mathrm{M})(\mathbf{G})$, followed by quantification, average fluorescence intensity of VDAC-1 per HLC (H). Data represent at least 3 independent experimental runs. Scale bar: $10 \mu \mathrm{m} . N=\sim 100-180$ cells in each group. Data represent 1 of 3 independent experiments and are shown as means \pm SEM. One-way ANOVA was used to compare means between groups followed by Tukey's post hoc comparisons. ${ }^{*} P<0.05,{ }^{*} P<0.01,{ }^{*}{ }^{*} P<0.001,{ }^{* * *} P<0.0001$. 

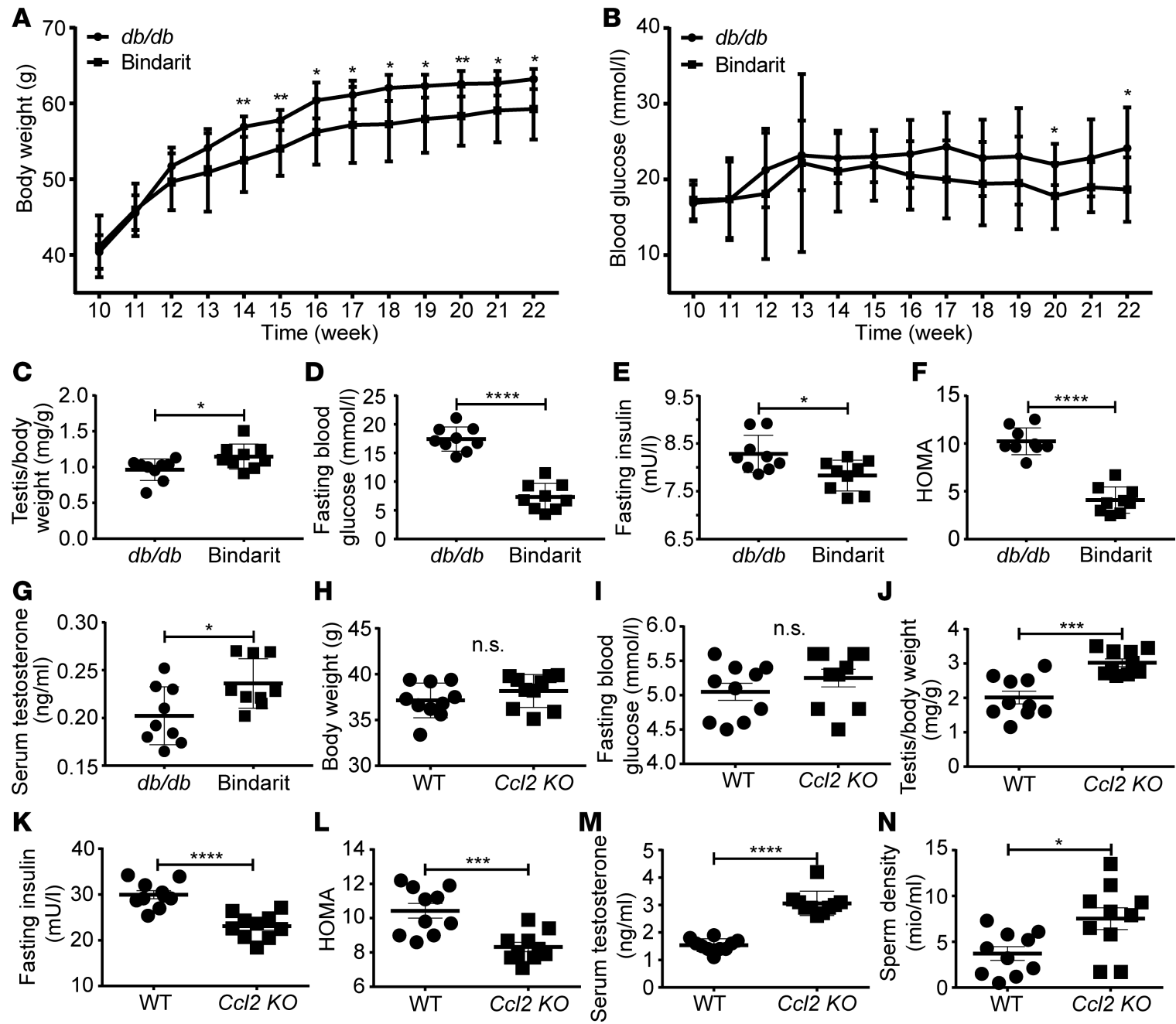

Figure 8. Pharmacological or genetic blockage of CCL2 ameliorated Met5 and hypogonadism. (A-C) $d b / d b$ mice were treated with vehicle or Bindarit (100 $\mathrm{mg} / \mathrm{kg} / \mathrm{d}$ ) for 12 weeks. Weekly body weight (A), weekly random blood glucose levels (B), testis/body weight ratio at 12 weeks posttreatment (C), fasting blood glucose (D), fasting insulin (E), homeostatic model assessment (HOMA) index (F), and testosterone level in serum (G) were recorded and/or calculated 12 weeks post-treatment. (H-N) WT and CCI2-KO mice were fed with a high-energy diet (HED) for 12 weeks. Body weight (H), fasting blood glucose (I), testis/body weight ratio (J) fasting insulin (K), HOMA index (L), serum testosterone (M), and sperm density (N) were recorded and/or calculated 12 weeks posttreatment. $N=9-14$ mice in each group. Data are shown as means \pm SEM. Student's 2-tailed $t$ test was used to compare means between 2 groups. ${ }^{*} P$ $<0.05,{ }^{* *} P<0.01,{ }^{* *} P<0.001,{ }^{* * *} P<0.0001$.

macrophages toward the M2 phenotype and sustains immune privilege in the testes (73). Increased abundance of corticosterone in the testis of $d b / d b$ mice explains the shift of the macrophage population to an antiinflammatory and more proapoptotic phenotype $(73,74)$ and fits the upregulated $I l-10$ phenotype $(75)$. This is a novel finding for the testis in subjects with MetS and will need further investigations. Nevertheless, upon chronic inflammation, the immune-privileged testis struggles to balance pro-and antiinflammation, in order to sustain normal functionality. Breaking this balance by inhibiting CCL2 expression could favor antiinflammation and improve reproduction in MetS-induced male subfertility.

Each MetS component can exert deleterious effects on male fertility separately. For instance, chronic inflammation in the adipose tissue of obese subjects correlates with the systemically increased production of reactive oxygen species $(76,77)$, which might diffuse into the testis and cause damages such as DNA fragmentation (78). Abnormal glucose homeostasis can interfere with the hypothalamo-pituitary-testicular axis and spermatogenesis and lead to reproductive impairment (79). Hyperglycemia contributes to endothelial dysfunction and results in organic erectile dysfunction (80), which might be partially responsible for the completely compromised fertility in $d b / d b$ mice. Furthermore, dyslipidemia may induce poor sperm quality as increasing serum lipids are inversely associated with serum testosterone level and sperm parameters $(81,82)$. 
Table 4. IVF with sperm from WT versus $C c / 2-K O$ males on an HED

\begin{tabular}{|c|c|c|c|c|}
\hline & Rate of degenerated oocytes after IVF & Cleavage rate & Developmental rate ${ }^{A}$ & Developmental rate ${ }^{\mathrm{B}}$ \\
\hline WT & $16.5 \pm 3.3$ & $58.9 \pm 6.5$ & $37.7 \pm 4.7$ & $46.0 \pm 6.0$ \\
\hline$C c / 2-K O$ & $17.6 \pm 4.5^{c}$ & $86.1 \pm 4.4^{D}$ & $75.5 \pm 6.3^{D}$ & $75.4 \pm 6.9^{D}$ \\
\hline
\end{tabular}

Although the pathogenesis of male subfertility in MetS is multifactorial and it is difficult to dissect the contribution from each one individually, it is plausible to assume that these components elicit combinatorial effects on male reproductivity. In this context, our present investigation indicates that promising outcomes can be achieved by targeting at least one of the complications of MetS.

The major limitation of our study is that we assumed the absence of Leydig cells after 12 weeks of age in the testis of $d b / d b$ mice was caused by the chronic inflammation with development of MetS. This hypothesis was supported by our in vitro models, but Leydig cells exhibiting dysfunction and apoptosis were not seen in the testis of $d b / d b$ mice in the present study. Future studies should use at least 1 more time point in between 6 and 12 weeks to determine the causes of Leydig cell loss in vivo. Similarly, macrophages also reduced in number in the testis of the $d b / d b$ mice, which probably resulted from Leydig cell dysfunction and loss (83), and we were unable to further address the feedback loop of Leydig cells and testicular macrophages in the context of MetS because of the missing time points. Another limitation of this study is that the observations from $C c l 2-K O$ mice might be caused by the constitutive whole-body deficiency of the $\mathrm{C} c \mathrm{2}$ gene. A testis-specific $\mathrm{C} c \mathrm{l} 2-\mathrm{KO}$ mouse would allow us to further dissect the local effects of CCL2 from its systemic physiological impacts.

It has been well established that chronic inflammation plays a role in the pathogenesis of obesityassociated metabolic disease. While MetS potentially affects male reproduction, we have a limited understanding of how MetS-related inflammation exerts its detrimental effects on male fertility. In this study we demonstrate CCL2 as a preferentially MetS-induced molecule in testis with paracrine effects on Leydig cells. $d b / d b$ mice display full MetS with obesity, adipose tissue inflammation, diabetes, and infertility. IL-1 $\beta$ and CCL2 suppress synthesis of androgens by inhibiting the activities of steroidogenic enzymes and ultimately induce apoptosis of Leydig cells. Altogether our study suggests that failed reproduction of $d b / d b$ mice is likely a direct consequence of Leydig cell malfunction that is caused by increased CCL2 level and that inhibiting CCL2 expression may represent a therapeutic approach to ameliorate the reproductive dysfunction associated with MetS in males.

\section{Methods}

Animals and reagents. Male BKS(D)-Lepr ${ }^{\mathrm{db}+/+} / \mathrm{JOrlRj}(d b / d b)$ mice and B6.129S4-Ccl2 ${ }^{\mathrm{m} 1 \mathrm{Rol}}(C c l 2-K O)$ were obtained from Charles River Laboratories. The $d b / d b$ mice with hyperglycemic $(>11.1 \mathrm{mmol} / \mathrm{L})$ fasting blood glucose levels were further examined. Age-matched BKS(D)-Lepr $r^{\mathrm{db}+/-} / \mathrm{JOrlRj}(\mathrm{db} /+)$ and C57BL6/N (WT) mice (Charles River Laboratories) served as controls. All animals were housed in groups of 3 to 4 animals at a temperature of $21^{\circ} \mathrm{C} \pm 1{ }^{\circ} \mathrm{C}$ with a 12 -hour light/12-hour dark cycle with free access to food and water. In the Bindarit intervention experiment, $d b / d b$ mice were treated daily by gavage from 10 to 22 weeks of age with vehicle (0.5\% methyl-cellulose) or Bindarit (2-methyl-2-[[1-(phenylmethyl)-1H-indazol-3-yl]methoxy]-propanoic acid) (Cayman Chemical) at $100 \mathrm{mg} / \mathrm{kg}$. The dosage of Bindarit was selected according to previous reports $(84,85)$. Body weight and random blood glucose were monitored weekly. Fasting (16 hours) blood glucose was recorded at the end of the experiment. Serum was collected for testosterone and insulin level analysis using testosterone chemiluminescence immunoassay kit (Beijing Furui Runkang Biotechnology Co. Ltd) and insulin chemiluminescence immunoassay kit (Beijing Furui Runkang Biotechnology Co. Ltd), respectively. Testes were isolated for histology study after sacrifice. In the HED experiment, Ccl2-KO mice, 6 weeks old, and age-matched WT mice were fed $5.228 \mathrm{kcal} / \mathrm{kg}, 16 \%$ calories from protein, $60 \%$ calories from saturated fat, and $24 \%$ calories from carbohydrates (Altromin) for 12 weeks. Body weight and fasting (16 hours) blood glucose were monitored weekly. At the end of the experimental period, animals 
A

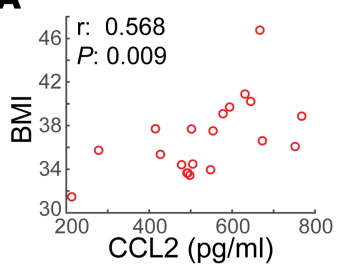

D
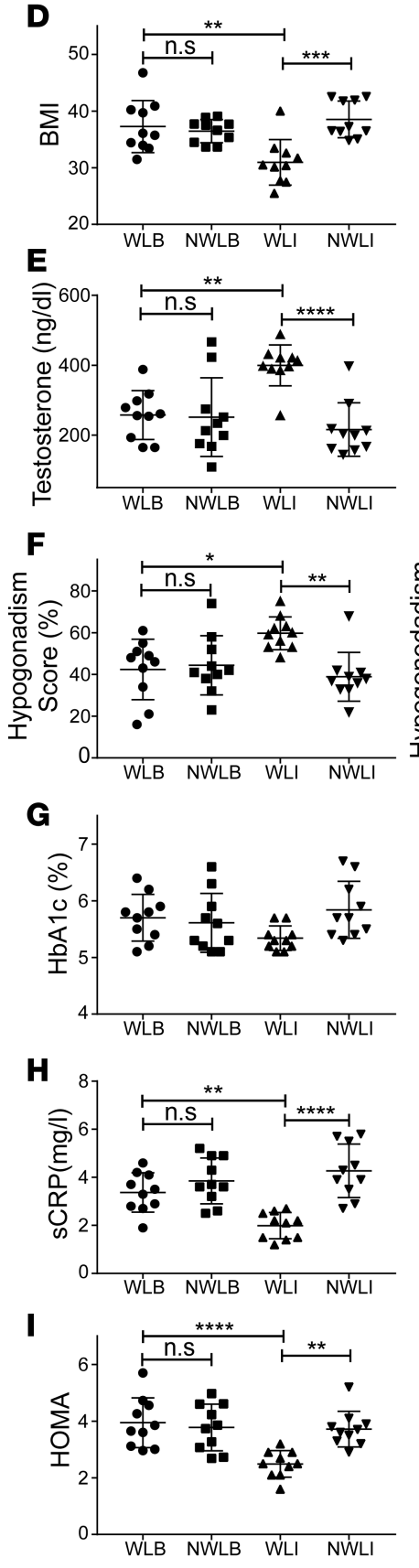
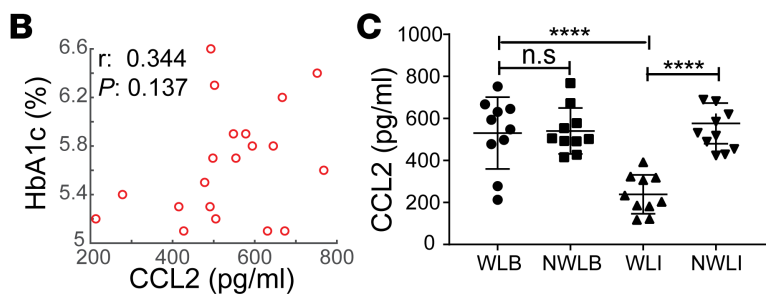

Correlation after intervention

Correlation of changes after intervention
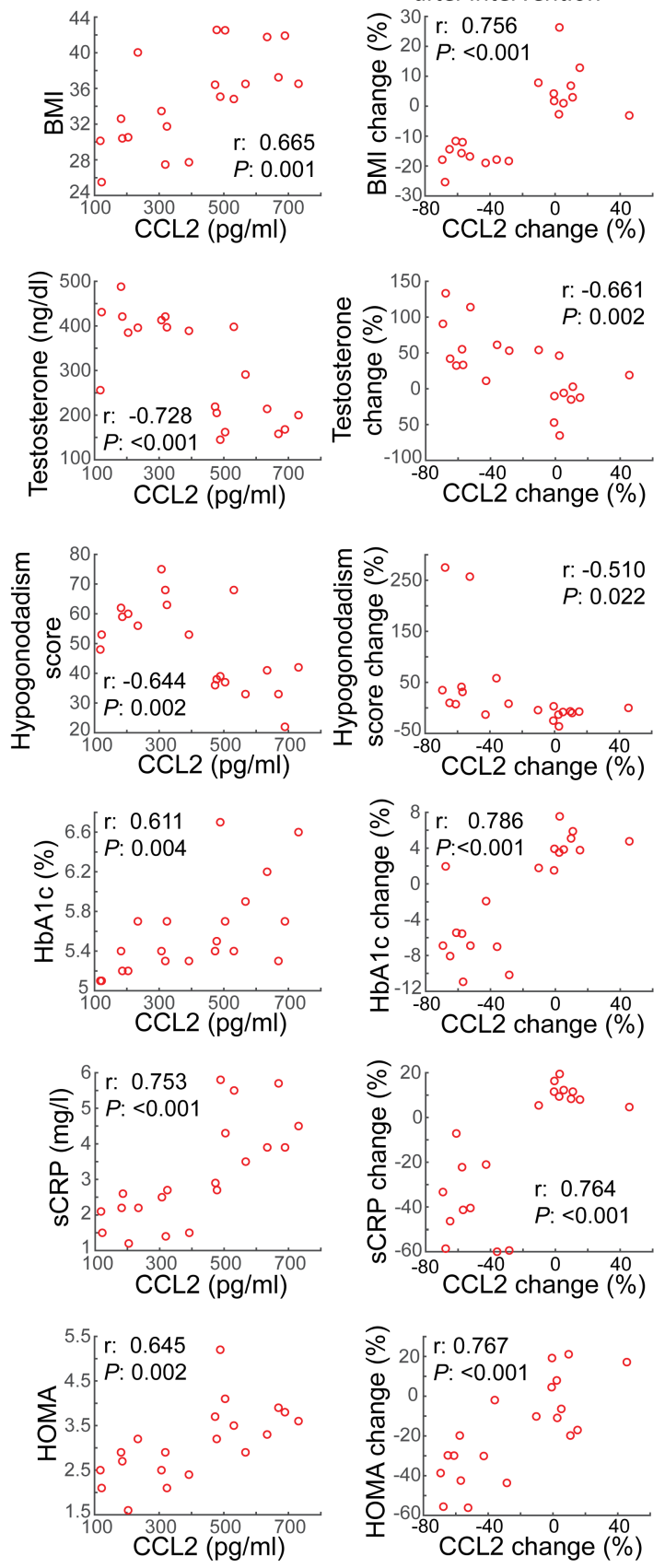

Figure 9. Clinical relevance of CCL2 in amelioration of MetS-related male hypogonadism. (A and B) Correlation of plasma CCL2 with BMI (A) and hemoglobin A1c (HbA1C) (B) at basal level in all participants $(n=20)$. (C) CCL2 levels in the weight loss after intervention group (WLI) was compared with its basal level (WLB), the non-weight loss after intervention group (NWLI) and its basal level (NWLB), respectively. (D-I) BMI (D), testosterone (E), hypogonadism score (F), HbA1c (C), sCRP (H), and HOMA (I) in different groups were compared at basal level and after intervention levels. Levels of each parameter after intervention were correlated to those of CCL2 (D-I, middle panels). Similar correlations were performed between changes of each parameter and those of CCL2 (basal vs. after intervention levels) (D-I, right panels). r, Pearson correlation coefficient. $N=10$ patients in each group. Data are shown as means \pm SEM. One-way ANOVA was used to compare means between 3 groups followed by Tukey's post hoc comparisons. ${ }^{*} P<0.05,{ }^{* *} P<0.01,{ }^{* * *} P<0.001,{ }^{* * *} P<0.0001$. 
were weighed at 8 am before euthanization by cervical dislocation under intraperitoneal ketamine/xylazine anesthesia. A total of 200-500 $\mu \mathrm{L}$ nonfasting blood was collected via the retroorbital venous plexus from all mice, and serum for biochemical determinations was generated by whole-blood centrifugation at $1300 \mathrm{~g}$ for 10 minutes. Testis and EWAT were excised. Unless stated otherwise, all reagents were obtained from MilliporeSigma Chemie $\mathrm{GmbH}$.

Assessment of fertility. Male $d b / d b$ or WT mice were mated to female WT breeders in individual groups at 12 weeks of age. Formation of the vaginal plug was considered as a sign of successful mating. Females were then monitored for resulting pregnancies, and number of litters was recorded after birth.

Assessment of mouse sperm parameters. In order to isolate mouse sperm, cauda epididymis was excised and then rinsed with $\mathrm{HS}$ medium (135 mM NaCl, $5 \mathrm{mM} \mathrm{KCl}, 2 \mathrm{mM} \mathrm{CaCl}, 1 \mathrm{mM} \mathrm{MgCl}, 30 \mathrm{mM} \mathrm{HEPES}, 10$ $\mathrm{mM}$ glucose, $10 \mathrm{mM}$ lactic acid, and $1 \mathrm{mM}$ pyruvic acid) and adjusted to $\mathrm{pH} 7.4$ with $\mathrm{NaOH}$. After transferring it to $1 \mathrm{~mL}$ of $\mathrm{HS}$ medium containing $5 \mathrm{mg} / \mathrm{mL}$ BSA and $15 \mathrm{mM} \mathrm{NaHCO}_{3}$, sperm were allowed to exude ( 15 minutes at $37^{\circ} \mathrm{C}, 5 \% \mathrm{CO}_{2}$ ) from incisions (20-23). Sperm count was carried out using Neubauer Improved camber. Sperm motility (rapidly progressive, slowly progressive, nonprogressive, and immotile) was assessed according to human sperm parameter guidelines $(20-23,86)$.

Superstimulation, cumulus-oocyte-complex collection, in vitro fertilization, and in vitro culture. CD-1 female mice, 6 to 8 weeks old, from Charles River Laboratories, were injected with 5 IU equine chorion gonadotropin and with 5 IU hCG 42-46 hours later. Cumulus-oocyte-complexes were collected from the ampullae of females 13-15 hours after hCG injection. For each biological replicate, oocytes from 3 female mice were pooled, and sperm from males, $d b / d b, C c l 2-K O$, or WT, was used for IVF. Sperm was collected from the cauda epididymis. Gametes were coincubated in HTF medium (Merck) for 4 hours. Degenerated oocytes were counted and excluded from subsequent in vitro culture. Fertilized oocytes were washed and cultured under mineral oil in a $37^{\circ} \mathrm{C}$ humidified atmosphere employing modified KSOM medium (Merck). At day 4, cleavage and developmental rates up to the blastocyst stage were recorded. Experiments were repeated at least 6 times.

Cell culture. Mouse Leydig tumor cell line (MLTC-1) cells were provided by Eveline Baumgart-Vogt (University of Giessen, Giessen, Germany). Cells were maintained in RPMI medium (Gibco, Thermo Fisher Scientific) with supplementation of $10 \%$ fetal bovine serum and 1\% Penicillin-Streptomycin-Glutamine (Thermo Fisher Scientific) (87). Primary HLC were cultured in Leydig Cell Medium (ScienCell). Cells were cultured at $37^{\circ} \mathrm{C}$ in $5 \% \mathrm{CO}_{2}(v / v)$ in the presence or absence of stimulators, additives, and/or inhibitors: $1 \mathrm{IU}$ hCG (Ferring), $1 \mathrm{ng} / \mathrm{mL}$ IL-1 $\beta$ (MilliporeSigma), and $100 \mu \mathrm{M}$ Bindarit (Cayman Chemical). Cells were processed for total RNA, protein isolation, single-molecule fluorescence in situ hybridization (sm-FISH), or immunofluorescence as described below.

Immunohistochemistry and immunofluorescence staining. Whole testes from mice were fixed in Bouin's fluid for 8 hours. Tissues were dehydrated in a graded series of ethanol and embedded in paraffin. Sections that were $7 \mu \mathrm{m}$ thick were processed for stainings. Sections were deparaffinized and rehydrated before antigen retrieval, followed by processing for antibody staining against the Leydig cell marker protein INSL3 (orb18041, AA range: 10-50, 1:100, Biorbyt) or the macrophage marker protein F4/80 (MCA497GA, Cl:A3-1, 1:500, $\mathrm{AbD}$ ). The stainings were developed using alkaline phosphatase (Dako, 1:200) followed by counterstain with Harris' hematoxylin and mounting under VectaMount AQ (Vector Laboratories). For immunofluorescence on tissues, sections were immunostained with antibodies against STAR (8849, 1:1000, clone D10H12, Cell Signaling Technology) or CCL2 (orb36895, 1:1000, Biorbyt) antibodies followed by detection with secondary antibodies (anti-rabbit IgG, 711295152, 1:400, Jackson ImmunoResearch; or anti-mouse IgG, SAB3701033, 1:400, MilliporeSigma) and counterstained with DAPI. For immunofluorescence on cells, cell smears were fixed in $4 \%$ paraformaldehyde and permeabilized in $70 \%$ ethanol. After that, slides were immunostained with antibodies against STAR, CCL2, or VDAC-1 (SAB5201374, clone S152B-23, 1:200, MilliporeSigma) followed by conjugation with the abovementioned secondary antibodies and counterstain with DAPI.

$R T-q P C R$. Total RNA from tissue (stored in RNAlater from Ambion, Thermo Fisher Scientific, at $-80^{\circ} \mathrm{C}$ ) or cell culture samples (harvested using RLT lysis buffer (QIAGEN) with $1 \% \beta$-mercaptoethanol) was extracted using the RNeasy Mini Kit from QIAGEN according to the manufacturer's instructions. RNA yield was quantified using a NanoDrop spectrophotometer (NanoDrop). Total RNA ( $1 \mu \mathrm{g})$ was used for reverse transcription in $20 \mu \mathrm{L}$ reactions using the SuperScript III VILO kit (Invitrogen, Thermo Fisher Scientific). RT-PCR amplifications were performed using the IQ SYBR Green Supermix (Bio-Rad Laboratories GmbH) on the StepOne Plus real-time PCR system (Applied Biosystems, Thermo Fisher Scientific). Furthermore, RT2 Profiler PCR Array Mouse Male Infertility (QIAGEN) was applied to examine expression levels of fertility-related genes. 
For PCR amplifications each well contained $5 \mu \mathrm{L}$ SYBR Green, $3.2 \mu \mathrm{L}$ RNase-free $\mathrm{H}_{2} \mathrm{O}, 0.3 \mu \mathrm{L}$ primer, and $1.5 \mu \mathrm{L}$ cDNA template. Cycling conditions were $95^{\circ} \mathrm{C}$ for 10 minutes, followed by 40 cycles at $95^{\circ} \mathrm{C}$ for 15 seconds, $60^{\circ} \mathrm{C}$ for 30 seconds, and $72^{\circ} \mathrm{C}$ for 30 seconds. The expression of each of the genes was measured in triplicate for each sample. PCR signal of the target transcript was normalized to the geometric mean of $\beta$-actin, and expression levels were assessed by relative quantification using the $2^{-\Delta \Delta \mathrm{Ct}}$ method (88). After assessment of the $2^{-\Delta \Delta C t}$ value, normalized data were corrected for outliers using the Grubb's test. Data are expressed as fold changes in gene expression relative to WT control transcripts. A complete list of primers used can be found in Supplemental Figure 1.

FISH. sm-FISH probes were designed using an online tool available at https://www.biosearchtech. com/products/rna-fish. 3'-amino modified oligonucleotides were obtained from LGC Biosearch. Pooled oligonucleotides were coupled to dyes and purified as described by Raj et al. (89). Fixed and permeabilized HLC were equilibrated in hybridization wash buffer ( $10 \%$ formamide in $2 \times$ SSC) and then incubated overnight in hybridization buffer (10\% formamide, $10 \%$ dextran sulfate, $2 \mathrm{mM}$ vanadyl-ribonucleoside complex, $0.02 \%$ RNase-free BSA, $0.001 \%$ Escherichia coli tRNA) with labeled mRNA probes at $37^{\circ} \mathrm{C}$. After incubation, cells were washed twice in hybridization wash buffer for 10 minutes, followed by mounting and imaging. Analysis of mRNA molecules was carried out using a modified system developed by Raj et al. (89). A complete list of sm-FISH probe sets used can be found in Supplemental Figure 2.

Western blot analysis. Tissue was lysed using NP-40 lysis buffer containing $20 \mathrm{mM}$ Tris/HCL (pH 7.5), $150 \mathrm{mM} \mathrm{NaCl}$, and 1\% $(v / v)$ NP-40 plus protease and phosphatase inhibitor cocktail (Thermo Fisher Scientific), followed by incubation on ice for 20 minutes. Debris were removed by a $20,000 \mathrm{~g}$ centrifugation at $4^{\circ} \mathrm{C}$ for 30 minutes. The supernatant was collected, and concentration of protein was determined with the Bradford Protein Assay (Bio-Rad). A total of $15 \mu \mathrm{g}$ protein was separated by $8 \%$ SDS-PAGE and electrophoretically transferred from the gel to a polyvinylidene difluoride membrane (MilliporeSigma) by semidry blotting (Bio-Rad). The membrane was blocked in $1 \times$ TBS containing $0.1 \%$ Tween and 5\% nonfat milk powder or BSA followed by overnight incubation with appropriate primary antibodies against STAR (8849, 1:1000, clone D10H12, Cell Signaling Technology), INSL3 (orb648755, 1:1000, Biorbyt), CCL2 (orb36895, 1:1000, Biorbyt), CYP17A1 (10443, 1:1000, clone E6Y3S, Cell Signaling Technology), and cleaved caspase-3 (9664, 1:1000, clone Asp175, Cell Signaling Technology), at $4^{\circ} \mathrm{C}$. All membranes were washed 3 times with $1 \times$ TBS with $0.1 \%$ Tween-20 (TBST) and incubated for 30 minutes at room temperature with goat anti-rabbit IgG horseradish peroxidase-conjugated secondary antibody (1:3000; Dako code P0448). After another 3 washes in TBST, the proteins were detected with enhanced chemiluminescence system (Thermo Fisher Scientific) and visualized by FUSION-Solo (PEQLAB, VWR).

Steroid concentrations in mouse. TIF was collected from WT and $d b / d b$ mice at 12-24 weeks of age. Testes were $50 \%$ decapsulated, placed into a $1.5 \mathrm{~mL}$ microcentrifuge tube with the exposed parenchyma up, and centrifuged $\left(12,000 \mathrm{~g}, 30\right.$ minutes, $\left.4^{\circ} \mathrm{C}\right)$. Supernatants were collected, snap-frozen, and stored at $-80^{\circ} \mathrm{C}$ until analysis. Collections averaged $4.0 \pm 0.3 \mu \mathrm{L} / 100 \mathrm{mg}$ testis. Gas chromatography-mass spectrometry (GC-MS) was performed to measure corticosterone and testosterone as described previously (90). Briefly, samples were equilibrated with deuterated internal standards, extracted using Extrelut NT columns, and purified using Sephadex LH-20 mini columns. Thereafter, heptafluorobutyrate derivatives were prepared. GC-MS was carried out on an Agilent Technologies 6890 series GC equipped with an Agilent Technologies 7683B automatic liquid sampler. The GC is directly interfaced to an Agilent Technologies 5975 inert XL mass selective detector. The following $\mathrm{m} / z$ ratios were measured for testosterone and corticosterone and their corresponding internal standards: $m / z 680.4 / 683.4$ for $\mathrm{T} / \mathrm{d} 3-\mathrm{T}$ and 720.4/726.4 for B/d8-B.

Flow cytometry (FACS) analysis. For flow cytometry analysis testis were kept in ice-cold PBS after excision. Tunica albuginea was removed, and single-cell suspensions were retrieved after collagenase enzymatic digestion of seminiferous tubules. Briefly, tubules were dissociated in $1.5 \mathrm{~mL}$ of type A collagenase (Roche) and DNase (Roche) with $10 \%$ FCS (GIBCO) at $37^{\circ} \mathrm{C}$ for 30 minutes. Cell suspension was resuspended and filtered through a $70 \mu \mathrm{m}$ cell strainer (BD). Red blood cells were removed by RBC lysis buffer (QIAGEN).

Testicular macrophage population was examined by FACSCanto II flow cytometer (Becton Dickinson). After exclusion of doublets, debris, and dead cells, immune cells were identified by using panleukocyte marker CD45 (103108, $2 \mu \mathrm{g} / \mathrm{mL}$, clone 30-F11, BioLegend). Macrophages were identified using F4/80 (123116, $5 \mu \mathrm{g} / \mathrm{mL}$, clone BM8, BioLegend) and CD64 antibodies $(139304,2 \mu \mathrm{g} / \mathrm{mL}$, clone X54-5/7.1, BioLegend). 
Acridine orange flow cytometry. Mouse epididymis was introduced to $800 \mu \mathrm{L}$ of TNE buffer $(150 \mathrm{mM}$ $\mathrm{NaCl}, 10 \mathrm{mM}$ Tris, $1 \mathrm{mM}$ EDTA, $\mathrm{pH}$ 7.4) in a Petri dish at room temperature immediately after extraction. After that, the tissue was cut several times and spermatozoa were washed out. Two aliquots of $300 \mu \mathrm{L}$ were flash-frozen in liquid nitrogen and stored at $-80^{\circ} \mathrm{C}$. The remaining sample was used for assessment of concentration and total sperm count.

Thawing of samples was done by diluting with the TNE buffer to adjust to $2 \times 10^{6} / \mathrm{mL}$ and mixing thoroughly. The sample was placed on ice immediately after thawing. Measurement of all samples was carried out within 1 hour after thawing on FACSTrack flow cytometer (Becton Dickinson) as previously described by Evenson and Jost (91), with minor modifications to increase the sensitivity of the assay: $100 \mu \mathrm{L}$ of sample kept on ice was mixed with $200 \mu \mathrm{L}$ of acid detergent for 10 minutes and then stained by adding $600 \mu \mathrm{L}$ of $6 \mu \mathrm{g} / \mathrm{mL}$ acridine orange in buffer and measured after 2.5 minutes. Samples were measured in batches of maximum 6 samples after equilibration of acridine orange within the flow cytometer and with adjusting of instrument settings according to the reference sample. All measurements were done in duplicates; a total of 5000 events excluding debris were collected in each run.

ELISA. IL-1 $\beta$ levels in whole testis lysates and CCL2 levels in mouse Leydig cell supernatant and whole testis lysates were measured using the mouse IL-1 $\beta$ ELISA kit (Wuhan Fine Biotech) or the mouse CCL2 ELISA kit (Wuhan Fine Biotech), respectively. In the clinical trial, the following indexes were determined: CCL2 (R\&D Systems, Bio-Techne), testosterone (DRG Instruments), sCRP (Abcam), glucose (MilliporeSigma), insulin (Abcam), and HbA1c (Crystal Chem), following manufacturers' instructions.

Statistics. Statistical analysis was performed using Graph Pad Prism 6 (GraphPad Software). Values in tables and graphs are expressed as mean \pm SEM (unless otherwise specified). Data were examined for normality of distribution and variance homogeneity. Two groups of mice were compared with Student's 2-tailed $t$ test for independent data. Age-dependent mouse and cell culture parameters were analyzed with 1 -way ANOVA to test the interaction between 3 or more groups. Where overall ANOVA showed significance, Tukey's post hoc comparisons between treatments were performed. $P<0.05$ ( ${ }^{*} P<0.05$, ${ }^{* *} P<0.01$, *** $P<0.001,{ }^{* * * *} P<0.0001$ ) was considered significant.

Study approval. Protocols for the Bindarit intervention experiments were approved by the Animal Research Committee of the Institute of Laboratory Animals, Chinese Academy of Medical Sciences Peking Union Medical College, Beijing, China. Protocols for the rest of the animal experiments were approved by the Animal Ethics Committee, University of Giessen. All animal experiments were conducted in accordance with the German Animal Welfare Act for the care and use of laboratory animals. Protocols for the clinical trial were approved by the Ethics Committee of Faculty of Medicine, University of Giessen.

\section{Author contributions}

QJ, TL, and CW conceived and designed the experiments. QJ, CCM, CW, PH, SB, YC, MFH, SAW, APD, and HCS performed the experiments. QJ, CCM, TL, CW, MFH, SAW, PH, and LS analyzed the data. QJ, TL, CCM, SFP, and LS wrote and edited the manuscript. QJ and TL are the guarantors of this work and, as such, had full access to all the data in the study and take responsibility for the integrity and the accuracy of the data analysis.

\section{Acknowledgments}

The authors thank Gundula Hertl, Birte Hussmann, Doris Erb, Tania Bloch, Kerstin Wilhelm, Franziska Kotarski, Barbara Fröhlich, Ming Wang, Lei Zhang, and Sanjay Tyagi for expert advice and technical assistance. This work was supported by grants from Deutsche Forschungsgemeinschaft to TL (DFG LI 353/17-1) and Bundesministerium für Bildung und Forschung to TL (01DL13015). The funders had no role in study design, data collection and analysis, decision to publish, or preparation of the manuscript. We acknowledge Life Science Editors and Ryan Dikdan for editing assistance.

Address correspondence to Thomas Linn, Clinical Research Unit, Centre of Internal Medicine, Justus-Liebig-University, Klinikstrasse 33, Giessen, Germany. Phone: 49.641.985.57017; Email: Thomas.Linn@ innere.med.uni-giessen.de.

QJ's present address is: Public Health Research Institute, New Jersey Medical School, Rutgers Biomedical and Health Sciences, Rutgers, The State University of New Jersey, Newark, New Jersey, USA. 
1. Agarwal A, Mulgund A, Hamada A, Chyatte MR. A unique view on male infertility around the globe. Reprod Biol Endocrinol. 2015;13:37.

2. Öztekin Ü, Caniklioğlu M, Sarı S, Selmi V, Gürel A, Işıkay L. Evaluation of male infertility prevalence with clinical outcomes in middle Anatolian region. Cureus. 2019;11(7):e5122.

3. Vermeulen A. Decreased androgen levels and obesity in men. Ann Med. 1996;28(1):13-15.

4. Kasturi SS, Tannir J, Brannigan RE. The metabolic syndrome and male infertility. J Androl. 2008;29(3):251-259.

5. Tavares RS, Portela JMD, Sousa MI, Mota PC, Ramalho-Santos J, Amaral S. High glucose levels affect spermatogenesis: an in vitro approach. Reprod Fertil Dev. 2017;29(7):1369-1378.

6. Bieniek JM, et al. Influence of increasing body mass index on semen and reproductive hormonal parameters in a multi-institutional cohort of subfertile men. Fertil Steril. 2016;106(5):1070-1075.

7. Fejes I, Koloszár S, Szöllosi J, Závaczki Z, Pál A. Is semen quality affected by male body fat distribution? Andrologia. 2005;37(5):155-159.

8. Jensen TK, et al. Body mass index in relation to semen quality and reproductive hormones among 1,558 Danish men. Fertil Steril. $2004 ; 82(4): 863-870$.

9. Magnusdottir EV, Thorsteinsson T, Thorsteinsdottir S, Heimisdottir M, Olafsdottir K. Persistent organochlorines, sedentary occupation, obesity and human male subfertility. Hum Reprod. 2005;20(1):208-215.

10. Fan Y, et al. Diet-induced obesity in male C57BL/6 mice decreases fertility as a consequence of disrupted blood-testis barrier. PLoS One. 2015;10(4):e0120775.

11. Cohen P, et al. Selective deletion of leptin receptor in neurons leads to obesity. J Clin Invest. 2001;108(8):1113-1121.

12. Chua SC, et al. Phenotypes of mouse diabetes and rat fatty due to mutations in the OB (leptin) receptor. Science. 1996;271(5251):994-996.

13. Haidl F, Haidl G, Oltermann I, Allam JP. Seminal parameters of chronic male genital inflammation are associated with disturbed sperm DNA integrity. Andrologia. 2015;47(4):464-469.

14. Du Plessis SS, Cabler S, McAlister DA, Sabanegh E, Agarwal A. The effect of obesity on sperm disorders and male infertility. Nat Rev Urol. 2010;7(3):153-161.

15. Dohle GR, et al. EAU guidelines on male infertility. Eur Urol. 2005;48(5):703-711.

16. Fijak M, et al. Infectious, inflammatory and 'autoimmune' male factor infertility: how do rodent models inform clinical practice? Hum Reprod Update. 2018;24(4):416-441.

17. Kajihara T, Okagaki R, Ishihara O. LPS-induced transient testicular dysfunction accompanied by apoptosis of testicular germ cells in mice. Med Mol Morphol. 2006;39(4):203-208.

18. Dandona P, Aljada A, Chaudhuri A, Mohanty P, Garg R. Metabolic syndrome: a comprehensive perspective based on interactions between obesity, diabetes, and inflammation. Circulation. 2005;111(11):1448-1454.

19. Weisberg SP, McCann D, Desai M, Rosenbaum M, Leibel RL, Ferrante AW. Obesity is associated with macrophage accumulation in adipose tissue. J Clin Invest. 2003;112(12):1796-1808.

20. Balistreri CR, Caruso C, Candore G. The role of adipose tissue and adipokines in obesity-related inflammatory diseases. Mediators Inflamm. 2010;2010:802078.

21. Hotamisligil GS, Shargill NS, Spiegelman BM. Adipose expression of tumor necrosis factor-alpha: direct role in obesity-linked insulin resistance. Science. 1993;259(5091):87-91.

22. Moschen AR, Molnar C, Enrich B, Geiger S, Ebenbichler CF, Tilg H. Adipose and liver expression of interleukin (IL)-1 family members in morbid obesity and effects of weight loss. Mol Med. 2011;17(7-8):840-845

23. Kanda H, et al. MCP-1 contributes to macrophage infiltration into adipose tissue, insulin resistance, and hepatic steatosis in obesity. J Clin Invest. 2006;116(6):1494-1505.

24. Welty FK, Alfaddagh A, Elajami TK. Targeting inflammation in metabolic syndrome. Transl Res. 2016;167(1):257-280.

25. Gerendai I, Banczerowski P, Csernus V, Halász B. Innervation and serotoninergic receptors of the testis interact with local action of interleukin-1beta on steroidogenesis. Auton Neurosci. 2007;131(1-2):21-27.

26. Reddy MM, et al. Bacterial lipopolysaccharide-induced oxidative stress in the impairment of steroidogenesis and spermatogenesis in rats. Reprod Toxicol. 2006;22(3):493-500.

27. Hutson JC. Secretion of tumor necrosis factor alpha by testicular macrophages. J Reprod Immunol. 1993;23(1):63-72

28. Moore C, Hutson JC. Physiological relevance of tumor necrosis factor in mediating macrophage-Leydig cell interactions. Endocrinology. 1994;134(1):63-69.

29. Harris S, et al. The presence of macrophages and inflammatory responses in an in vitro testicular co-culture model of male reproductive development enhance relevance to in vivo conditions. Toxicol In Vitro. 2016;36:210-215.

30. Aubry F, Habasque C, Satie AP, Jégou B, Samson M. Expression and regulation of the CC-chemokine monocyte chemoattractant protein-1 in rat testicular cells in primary culture. Biol Reprod. 2000;62(5):1427-1435

31. Gerdprasert O, O’Bryan MK, Nikolic-Paterson DJ, Sebire K, de Kretser DM, Hedger MP. Expression of monocyte chemoattractant protein-1 and macrophage colony-stimulating factor in normal and inflamed rat testis. Mol Hum Reprod. 2002;8(6):518-524

32. Kim CS, et al. Circulating levels of MCP-1 and IL-8 are elevated in human obese subjects and associated with obesity-related parameters. Int J Obes (Lond). 2006;30(9):1347-1355.

33. Christiansen T, Richelsen B, Bruun JM. Monocyte chemoattractant protein-1 is produced in isolated adipocytes, associated with adiposity and reduced after weight loss in morbid obese subjects. Int J Obes (Lond). 2005;29(1):146-150.

34. Sartipy P, Loskutoff DJ. Monocyte chemoattractant protein 1 in obesity and insulin resistance. Proc Natl Acad Sci U S A. 2003;100(12):7265-7270.

35. Kanda H, et al. MCP-1 contributes to macrophage infiltration into adipose tissue, insulin resistance, and hepatic steatosis in obesity. J Clin Invest. 2006;116(6):1494-1505.

36. Luciano-Mateo F, et al. Chemokine (C-C motif) ligand 2 gene ablation protects low-density lipoprotein and paraoxonase-1 double deficient mice from liver injury, oxidative stress and inflammation. Biochim Biophys Acta Mol Basis Dis. 2019;1865(6):1555-1566.

37. Nicolas N, et al. Testicular activin and follistatin levels are elevated during the course of experimental autoimmune epididymo-orchitis in mice. Sci Rep. 2017;7:42391. 
38. de Luca C, et al. Complete rescue of obesity, diabetes, and infertility in $\mathrm{db} / \mathrm{db}$ mice by neuron-specific LEPR-B transgenes. J Clin Invest. 2005;115(12):3484-3493.

39. Yabiku K, Nakamoto K, Tokushige A. Reintroducing testosterone in the $\mathrm{db} / \mathrm{db}$ mouse partially restores normal glucose metabolism and insulin resistance in a leptin-independent manner. BMC Endocr Disord. 2018;18(1):38

40. Saadat N, IglayReger HB, Myers MG, Bodary P, Gupta SV. Differences in metabolomic profiles of male db/db and s/s, leptin receptor mutant mice. Physiol Genomics. 2012;44(6):374-381.

41. Kowalski TJ, Liu SM, Leibel RL, Chua SC. Transgenic complementation of leptin-receptor deficiency. I. Rescue of the obesity/ diabetes phenotype of LEPR-null mice expressing a LEPR-B transgene. Diabetes. 2001;50(2):425-435.

42. Coleman DL. Obese and diabetes: two mutant genes causing diabetes-obesity syndromes in mice. Diabetologia. 1978;14(3):141-148

43. Shoshan-Barmatz V, Krelin Y, Chen Q. VDAC1 as a player in mitochondria-mediated apoptosis and target for modulating apoptosis. Curr Med Chem. 2017;24(40):4435-4446.

44. Lee B, et al. Impaired spermatogenesis and fertility in mice carrying a mutation in the Spink2 gene expressed predominantly in testes. J Biol Chem. 2011;286(33):29108-29117.

45. Pilatz A, et al. Metabolic syndrome and the seminal cytokine network in morbidly obese males. Andrology. 2017;5(1):23-30.

46. Borges BC, et al. Obesity-induced infertility in male mice is associated with disruption of Crisp4 expression and sperm fertilization capacity. Endocrinology. 2017;158(9):2930-2943.

47. Ghanayem BI, Bai R, Kissling GE, Travlos G, Hoffler U. Diet-induced obesity in male mice is associated with reduced fertility and potentiation of acrylamide-induced reproductive toxicity. Biol Reprod. 2010;82(1):96-104.

48. Fernandez CD, et al. Diet-induced obesity in rats leads to a decrease in sperm motility. Reprod Biol Endocrinol. 2011;9:32.

49. Tena-Sempere M, et al. Molecular mechanisms of leptin action in adult rat testis: potential targets for leptin-induced inhibition of steroidogenesis and pattern of leptin receptor messenger ribonucleic acid expression. J Endocrinol. 2001;170(2):413-423.

50. Wong SK, Chin KY, Suhaimi FH, Fairus A, Ima-Nirwana S. Animal models of metabolic syndrome: a review. Nutr Metab (Lond). 2016;13:65.

51. Kennedy AJ, Ellacott KL, King VL, Hasty AH. Mouse models of the metabolic syndrome. Dis Model Mech. 2010;3(3-4):156-166

52. Palmer NO, Bakos HW, Owens JA, Setchell BP, Lane M. Diet and exercise in an obese mouse fed a high-fat diet improve metabolic health and reverse perturbed sperm function. Am J Physiol Endocrinol Metab. 2012;302(7):E768-E780.

53. Craig JR, Jenkins TG, Carrell DT, Hotaling JM. Obesity, male infertility, and the sperm epigenome. Fertil Steril. 2017;107(4):848-859.

54. Azenabor A, Ekun AO, Akinloye O. Impact of inflammation on male reproductive tract. J Reprod Infertil. 2015;16(3):123-129.

55. Morales V, et al. Intratesticular delivery of tumor necrosis factor-alpha and ceramide directly abrogates steroidogenic acute regulatory protein expression and Leydig cell steroidogenesis in adult rats. Endocrinology. 2003;144(11):4763-4772.

56. Lysiak JJ, Nguyen QA, Kirby JL, Turner TT. Ischemia-reperfusion of the murine testis stimulates the expression of proinflammatory cytokines and activation of c-jun N-terminal kinase in a pathway to E-selectin expression. Biol Reprod. 2003;69(1):202-210

57. Nov $\mathrm{O}$, et al. Interleukin- $1 \beta$ regulates fat-liver crosstalk in obesity by auto-paracrine modulation of adipose tissue inflammation and expandability. PLoS One. 2013;8(1):e53626.

58. Cherian S, Lopaschuk GD, Carvalho E. Cellular cross-talk between epicardial adipose tissue and myocardium in relation to the pathogenesis of cardiovascular disease. Am J Physiol Endocrinol Metab. 2012;303(8):E937-E949.

59. Zhu Q, Scherer PE. Immunologic and endocrine functions of adipose tissue: implications for kidney disease. Nat Rev Nephrol. 2018;14(2):105-120.

60. Sharma M, et al. Enhanced glycolysis and HIF-1 $\alpha$ activation in adipose tissue macrophages sustains local and systemic interleukin-1 $\beta$ production in obesity. Sci Rep. 2020;10(1):5555.

61. Kamei N, et al. Overexpression of monocyte chemoattractant protein-1 in adipose tissues causes macrophage recruitment and insulin resistance. J Biol Chem. 2006;281(36):26602-26614.

62. Nam BY, et al. The MCP-1/CCR2 axis in podocytes is involved in apoptosis induced by diabetic conditions. Apoptosis. 2012;17(1):1-13.

63. Nakazawa T, et al. Monocyte chemoattractant protein 1 mediates retinal detachment-induced photoreceptor apoptosis. Proc Natl Acad Sci U S A. 2007;104(7):2425-2430.

64. Dominy JE, Hwang J, Stipanuk MH. Overexpression of cysteine dioxygenase reduces intracellular cysteine and glutathione pools in HepG2/C3A cells. Am J Physiol Endocrinol Metab. 2007;293(1):E62-E69.

65. Gerald D, et al. JunD reduces tumor angiogenesis by protecting cells from oxidative stress. Cell. 2004;118(6):781-794.

66. Udensi UK, Tchounwou PB. Oxidative stress in prostate hyperplasia and carcinogenesis. J Exp Clin Cancer Res. 2016;35(1):139.

67. Shen H, Sikorska M, Leblanc J, Walker PR, Liu QY. Oxidative stress regulated expression of ubiquitin Carboxyl-terminal Hydrolase-L1: role in cell survival. Apoptosis. 2006;11(6):1049-1059.

68. Chen $\mathrm{H}$, et al. Inhibition of VDAC1 prevents $\mathrm{Ca}^{2}+$-mediated oxidative stress and apoptosis induced by 5 -aminolevulinic acid mediated sonodynamic therapy in THP-1 macrophages. Apoptosis. 2014;19(12):1712-1726

69. Hutson JC. Changes in the concentration and size of testicular macrophages during development. Biol Reprod. 1990;43(5):885-890.

70. Swierczynska MM, et al. Changes in morphology and function of adrenal cortex in mice fed a high-fat diet. Int J Obes (Lond). 2015;39(2):321-330

71. Friedman JE, et al. Phosphoenolpyruvate carboxykinase (GTP) gene transcription and hyperglycemia are regulated by glucocor ticoids in genetically obese $\mathrm{db} / \mathrm{db}$ transgenic mice. J Biol Chem. 1997;272(50):31475-31481.

72. Barnes PJ. Anti-inflammatory actions of glucocorticoids: molecular mechanisms. Clin Sci (Lond). 1998;94(6):557-572.

73. Wang M, et al. Characterization of the micro-environment of the testis that shapes the phenotype and function of testicular macrophages. J Immunol. 2017;198(11):4327-4340

74. Varga G, et al. Glucocorticoids induce an activated, anti-inflammatory monocyte subset in mice that resembles myeloid-derived suppressor cells. J Leukoc Biol. 2008;84(3):644-650.

75. Lumeng CN, Bodzin JL, Saltiel AR. Obesity induces a phenotypic switch in adipose tissue macrophage polarization. J Clin Invest. 2007;117(1):175-184.

76. Alcalá M, et al. Increased inflammation, oxidative stress and mitochondrial respiration in brown adipose tissue from obese 
mice. Sci Rep. 2017;7(1):16082.

77. Furukawa S, et al. Increased oxidative stress in obesity and its impact on metabolic syndrome. J Clin Invest. 2004;114(12):1752-1761.

78. Guerriero G, Trocchia S, Abdel-Gawad FK, Ciarcia G. Roles of reactive oxygen species in the spermatogenesis regulation. Front Endocrinol (Lausanne). 2014;5:56.

79. Baccetti B, et al. Insulin-dependent diabetes in men is associated with hypothalamo-pituitary derangement and with impairment in semen quality. Hum Reprod. 2002;17(10):2673-2677.

80. Maiorino MI, Bellastella G, Esposito K. Diabetes and sexual dysfunction: current perspectives. Diabetes Metab Syndr Obes. 2014; 7:95-105.

81. Hagiuda J, Ishikawa H, Furuuchi T, Hanawa Y, Marumo K. Relationship between dyslipidaemia and semen quality and serum sex hormone levels: an infertility study of 167 Japanese patients. Andrologia. 2014;46(2):131-135

82. Shalaby MA, el-Zorba HY, Kamel GM. Effect of alpha-tocopherol and simvastatin on male fertility in hypercholesterolemic rats. Pharmacol Res. 2004;50(2):137-142.

83. Meinhardt A, et al. Local regulation of macrophage subsets in the adult rat testis: examination of the roles of the seminiferous tubules, testosterone, and macrophage-migration inhibitory factor. Biol Reprod. 1998;59(2):371-378.

84. Bhatia M, Ramnath RD, Chevali L, Guglielmotti A. Treatment with bindarit, a blocker of MCP-1 synthesis, protects mice against acute pancreatitis. Am J Physiol Gastrointest Liver Physiol. 2005;288(6):G1259-G1265.

85. Chen W, et al. Bindarit, an inhibitor of monocyte chemotactic protein synthesis, protects against bone loss induced by chikungunya virus infection. J Virol. 2015;89(1):581-593.

86. Cooper TG, et al. World Health Organization reference values for human semen characteristics. Hum Reprod Update. 2010;16(3):231-245.

87. Rebois RV. Establishment of gonadotropin-responsive murine leydig tumor cell line. J Cell Biol. 1982;94(1):70-76.

88. Schmittgen TD, Livak KJ. Analyzing real-time PCR data by the comparative C(T) method. Nat Protoc. 2008;3(6):1101-1108

89. Raj A, van den Bogaard P, Rifkin SA, van Oudenaarden A, Tyagi S. Imaging individual mRNA molecules using multiple singly labeled probes. Nat Methods. 2008;5(10):877-879.

90. Wudy SA, Hartmann M, Homoki J. Determination of 11-deoxycortisol (Reichstein's compound S) in human plasma by clinical isotope dilution mass spectrometry using benchtop gas chromatography-mass selective detection. Steroids. 2002;67(10):851-857.

91. Evenson D, Jost L. Sperm chromatin structure assay for fertility assessment. Curr Protoc Cytom. 2001;Chapter 7:Unit 7.13. 